\title{
A Metal-Free Carbon-Based Catalyst: An Overview and Directions for Future Research
}

\author{
Pitchaimani Veerakumar ${ }^{1,2, *}$, Pounraj Thanasekaran ${ }^{3}{ }^{(\mathbb{C}}$, Thiruvengadam Subburaj ${ }^{4}$ and \\ King-Chuen Lin ${ }^{1,2, *}$ \\ 1 Department of Chemistry, National Taiwan University, Taipei 10617, Taiwan \\ 2 Institute of Atomic and Molecular Sciences, Academia Sinica, Taipei 10617, Taiwan \\ 3 Institute of Chemistry, Academia Sinica, Taipei 11529, Taiwan; ptsekaran@gmail.com \\ 4 Department of Chemical Engineering, National Taiwan University, Taipei 10617, Taiwan; \\ aztecagain@gmail.com \\ * $\quad$ Correspondence: spveerakumar@gmail.com (P.V.); kclin@ntu.edu.tw (K.-C.L.); Tel.: +886-2-2366-8289 (P.V.); \\ $+886-2-3366-1162$ (K.-C.L.)
}

Received: 27 August 2018; Accepted: 19 September 2018; Published: 27 September 2018

\begin{abstract}
Metal-free carbon porous materials (CPMs) have gained the intensive attention of scientists and technologists because of their potential applications, ranging from catalysis to energy storage. Various simple and facile strategies are proposed for the preparation of CPMs with well-controlled sizes, shapes, and modifications on the surface. The extraordinary tenability of the pore structure, the environmental acceptability, the unique surface and the corrosion resistance properties allow them to be suitable materials for a large panel of catalysis applications. This review briefly outlines the different signs of progresses made towards synthesizing CPMs, and their properties, including catalytic efficiency, stability, and recyclability. Finally, we make a comparison of their catalytic performances with other nanocomposites, and we provide an outlook on the expected developments in the relevant research works.
\end{abstract}

Keywords: graphene; graphene oxide; porous carbon; graphitic carbon nitride; metal-free catalysts; recyclability; stability

\section{Introduction}

Carbon porous materials (CPMs) play an increasingly critical role in science and technical applications ranging from sensors to energy storage [1-4]. Considering the business cost and energy/environmental concerns, the use of CPMs as catalysts for a variety of heterogeneous catalysis applications becomes one of the hot topics [5]. The reason behind is that they have desirable unique properties such as a large surface area, meso-/micro-porosity, a large pore volume, chemical inertness, high stability, high electrical conductivity, etc. [6]. Mostly, graphitic or porous carbons are used for applications in catalysis, sensors, and sorption. Apart from this, carbon surface chemistry (surface oxygen, and other heteroatoms, amphoteric character, and hydrophobicity) and the controlled pore structure of carbons are very important for catalysis applications. In the last few years, graphitic carbon nanosheets and heteroatom-doped or activated carbon nanosheets acting as carbocatalysts or direct catalysts (i.e., metal-free catalyst), have been developed [7-10].

Carbon-based materials including amorphous carbon, carbon fibers ( $\mathrm{CFs})$, activated carbon (ACs) ordered mesoporous carbon (OMCs), graphene oxide (GO), carbon black (CB), carbon nanotubes (CNTs), and carbon nanodots (CNDs) offer new possibilities for the developments of many catalytic supports and catalytic performances [11-13]. A considerable effort towards the development of aerobic oxidation reactions has emerged as a promising alternative [14-17]. For instance, 
oxidation of alcohols [18-20], amines [21], and thiols or sulphides were conducted under mild conditions [22,23]. A wide range of homogeneous and heterogeneous transition metal-based catalysts have been developed for several organic transformations. Unfortunately, many of those metals are rare, expensive, and/or toxic, thus imposing challenges on sustainable and environmental issues. In contrast, metal-free carbon-based materials are eco-friendly and abundant, and readily available heterogeneous catalysts for organic reactions. In carbon-based materials, the carbon-bonded structures give a major contribution to induce the catalytic processes. For example, graphite oxide (GO) or functionalized graphene oxide materials are widely and successfully used in oxidation reactions, [24-26], olefin hydrogenation [27], Friedel-Crafts reactions [28,29], Mukaiyama-Michael additions [30,31], polymerizations [32], crosslinking reactions [33], epoxide ring-opening reactions [34,35], one-pot reactions [36], and multi-component reactions [37,38] owing to their low cost, structural tunability, huge $\pi$-conjugation, and co-existence of nitrogen and oxygen groups in the graphene (Gr) sheets, along with structural defects and active sites provided by various dopants [39-43]. Very recently, GO has drawn attention as a metal-free catalyst for synthesizing 1,5-benzodiazepines [44] because it possesses a large specific surface area with many oxygen functional groups (carboxyl, hydroxyl, epoxide, and lactone), and therefore, GO can be considered as a potential catalyst for synthesis of some biologically and pharmacologically relevant benzodiazepine compounds. Mohammedi and co-workers [45] have reviewed the use of porous GO and sulfonated Gr as metal-free heterogeneous nanocatalysts in several organic reactions as they showed several advantages such as good dispersion, adsorption of the reagent, and desorption of the product in a fast manner. The boundless growth on "graphene-based metal-free catalysis" is depicted in Figure 1 which shows the annual number of publications using "Graphene-based nanomaterials as heterogeneous acid catalysts: a comprehensive perspective" provided by Scopus database. These numbers indicate the very rapid growth of graphene publications, and the parallel growth of publications related to metal-free catalysis applications [45].

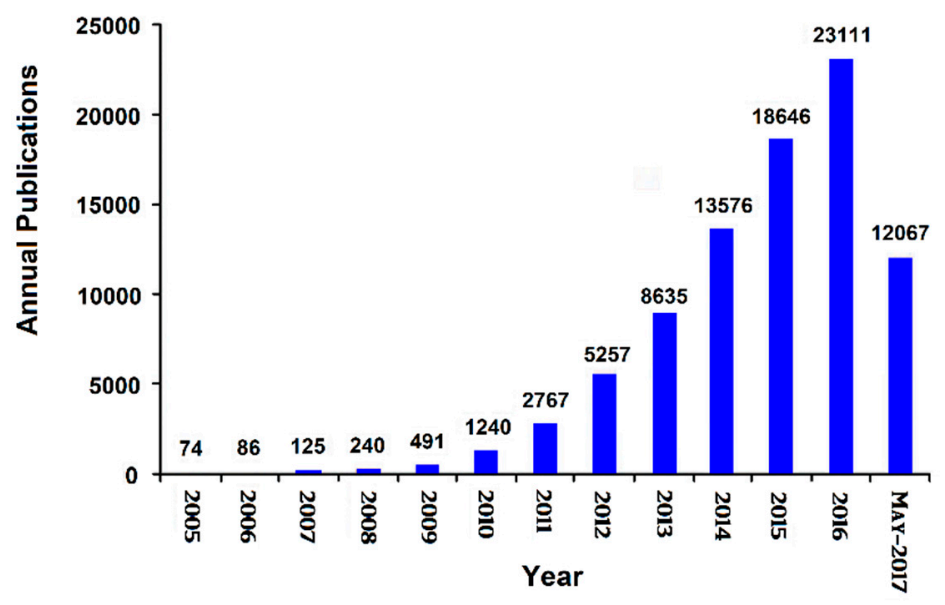

Figure 1. Annual number of publications obtained from a Scopus search using "graphene and catalysis" as keywords [45]. Reprinted with permission from [45]. The Royal Society of Chemistry, 2017.

Graphitic carbon nitrides (GCN) are highly attractive for their outstanding optical and electrocatalytic characteristics, as well as increased potential uses. [46]. Since they possess the advantages of low-cost, lightweight, easy availability, and remarkable stability, they have been applied in water splitting, photocatalysis, sensing, bio-imaging, etc. [47]. In addition, the polymeric nature of GCN is also suitable for a metal-free catalyst, which has been used in a wide range of electrochemical sensing of biomolecules, phenolic compounds, and photocatalyst. Among them, the photocatalyst is being actively studied. Compared to Gr or GOs, they have similar or larger surface areas. Their electronic and surface properties, which determine their catalytic performance, can also be fine-tuned via heteroatom doping [48]. More importantly, their large-scale production for metal-free catalytic applications can be achieved at much lower cost and without involving metal catalysts [49]. 
However, GCN is one of the most prominent materials because of its suitable band structure containing the optical band gap of about $2.70-2.90 \mathrm{eV}$, which corresponds to the wavelength of $460-430 \mathrm{~nm}$, and low electrical conductivity $\left(\sim 0.9 \times 10^{-9} \mathrm{~S} \mathrm{~m}^{-1}\right)$ [50]. To enhance the catalytic performance, narrowed band gap can be observed for GCN upon doping with different elements such as sulfur, phosphorous, oxygen and boron. Recently, GCN-based nanocomposites have been engaged for the photocatalytic decomposition of aqueous organic pollutants, and the details have been reviewed [51].

Activated carbons (ACs) are carbonaceous materials that are capable of tailoring their porous internal structure and surface chemistry [52]. Material properties of this ACs can be tuned by modification treatments to obtain superior catalytic performances [53]. Especially, functionalization of ACs influences the surface behavior, in addition to their relevant features for catalytic reactions. Since these functional groups behave as active sites, the nature and concentration of these groups play major roles in determining its application as acid catalysts [54]. These materials were used as catalysts in several reactions including the oxidative dehydrogenation of hydrocarbons [55], hydrogenation of hydrocarbon [56], alcohols dehydrogenation [57], reduction of NOx [58], oxidation of SOx [59,60], ozonation [61], and catalytic wet air oxidation [62,63]. The presence of nitrogen andoxygen-carrying functionalities in ACs facilitates their dispersion in water and polar solvents, as well as interrupts the regular electron distribution. These unique characteristics make hetero-atom-doped ACs a potent material for the immobilization of various nanoparticles, polymeric composites, and catalytic activities $[64,65]$. Significant progress towards developing N-doped porous carbon (NPC) nanomaterials with superior activity in hydrogenation and oxidation reactions was made. These improvements have been mini-reviewed by Li and coworkers [66].

\section{Graphene Nanocomposites for Catalysis}

In recent years, graphene and element-doped graphene-based materials have attracted significant importance in metal-free catalysis, owing to their unique structures, active sites, large surface area, and electronic properties [67,68]. Many efforts have been undertaken to use these materials in various reactions including alkene hydrogenation, amination, oxidation, reduction of nitrobenzene, acetophenone, etc. [69-71]. For instance, doped graphene has been employed as a carbocatalyst for selective hydrocarbon, styrene, and cyclooctane oxidation [72], while N-doped graphene materials have gained substantial attention as catalysts for the hydrochlorination of acetylene [73]. Recently, the best transesterification conversion of glyceryl trioleate was observed using an aquivion-carbon composite as a catalyst in methanol at mild conditions [74]. In another study, carbon blacks act as effective metal-free catalysts for the conversion of olefins to alkanes using a reducing agent, hydrazine [13].

Zhang et al. reported that primary amine-functionalized GO (AP-GO) is an inexpensive and effective metal-free catalyst for the one-pot Henry-Michael reaction of benzaldehyde and nitromethane into trans-nitrostyrene, which on further reaction with malononitrile, affords 2-(2-nitro-1-phenylethyl) malononitrile in a good yield (87\%) [75]. In this reaction, the synergy of carboxyl and amine functional groups presented on $\mathrm{GO}$ at $100{ }^{\circ} \mathrm{C}$ led to the excellent catalytic performance with high selectivity (Scheme 1). Notably, these functional groups on GO might strengthen the interaction with the bases to react strongly with the starting materials. In addition, it showed a higher catalytic activity than those using other amine-functionalized carbon catalysts, and it can be reused six times. 


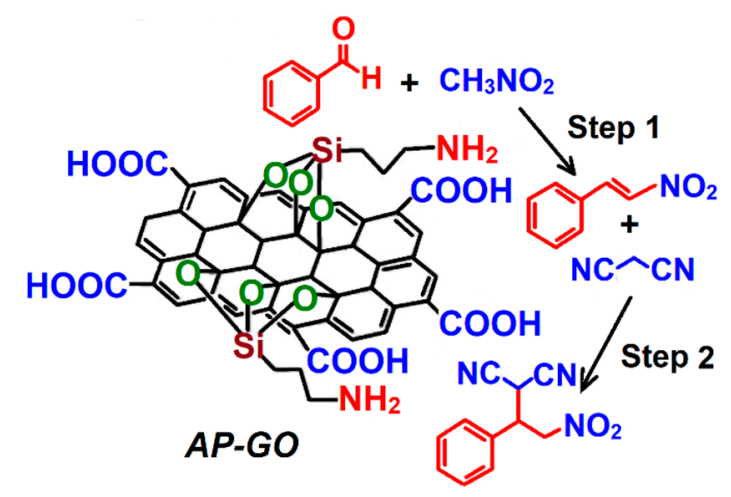

Scheme 1. One-pot Henry-Michael reaction using a primary amine-functionalized graphene oxide (GO) catalyst. From Zhang et al. [75]. Reprinted with permission from [75]. The American Chemical Society, 2015.

Kumari et al. used GO nanosheets as an effective catalyst for the one-pot synthesis of aromatic amides at a reflux temperature condition to give moderate-to-good yields (60-82\%) within 8-14 $\mathrm{h}$ (Scheme 2). They employed both electron-rich and -poor aromatic aldehydes for this reaction. The electron-poor substituents occupied at the ortho- and para-positions producing the desired amides in excellent yields. Moreover, the reusability of this catalyst was investigated up to six catalytic cycles in the synthesis of amide derivatives. Furthermore, the reaction mechanism of this reaction was suggested and discussed [76].

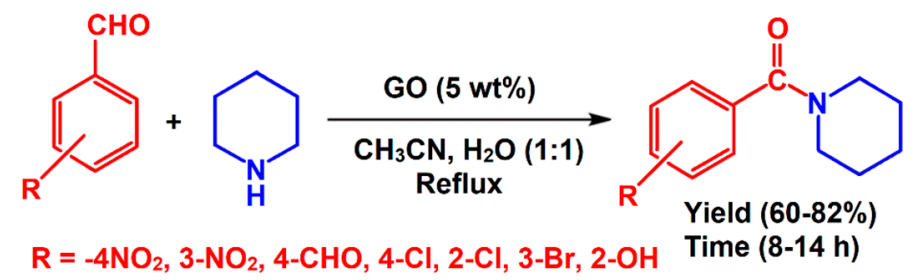

Scheme 2. Synthesis of amides catalyzed by GO.

\section{1. $C-N$ Coupling Reaction}

Since these nanocomposites show a remarkable catalytic performance upon increasing active sites, the growth of metal-free catalysts seems to be explosive nowadays. For example, Zhang et al. reported first that an acid-base bifunctional catalyst using - $\mathrm{COOH}$ and $-\mathrm{NH}_{2}$ on the edge and basal surface of GO, respectively, showed an excellent catalytic performance in deacetalization-Knoevenagel reaction because of their unique two-dimensional (2D) structure containing low mass transfer resistance and surface acidity of carbons (Scheme 3). In addition, amine functionalized-activated carbon, -silica and -alumina nanocomposites were also subjected to this reaction, which resulted in moderate yields when compared to $\mathrm{NH}_{2}-\mathrm{GO}$. The $\mathrm{N}$ content study confirmed the successful grafting of amines onto the GO surface. The recovered catalysts could be reused at least six times [77]. This type of catalyst provides advantages such as the absence of transition metals, more surface area and excellent activity. 


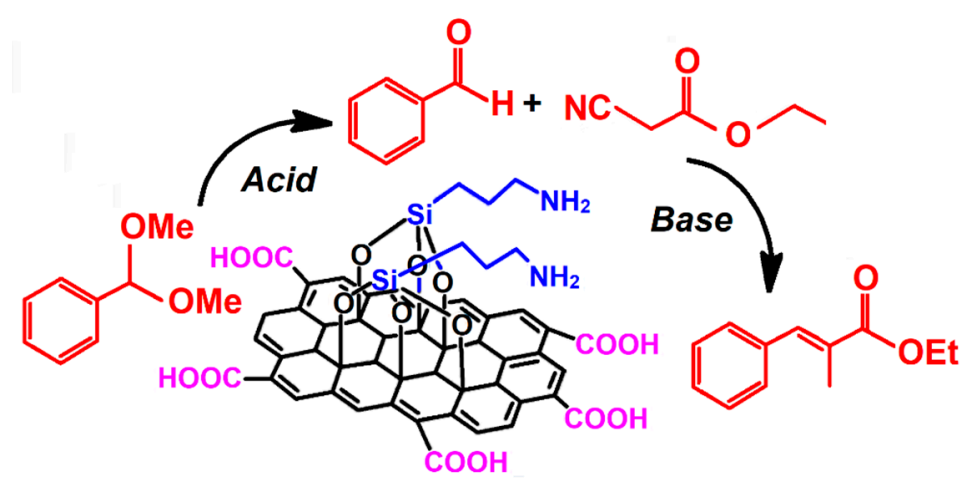

Scheme 3. One-pot deacetalization-Knoevenagel reaction using an acid-base bifunctional catalyst. From Zhang et al. [77]. Reprinted with permission from [77]. The American Chemical Society, 2014.

In 2017, the catalytic performance of GO was harnessed for the reaction of $\alpha$-ketoaldehyde and primary/secondary amines to afford $\alpha$-ketoamides via a cross-dehydrogenative coupling (CDC) pathway (Scheme 4) [78]. Under optimized conditions, the substituted activated aldehydes underwent a reaction with a variety of amines to give $>90 \%$ yields. In this reaction, the product yield was not altered upon changing the substituents in the phenyl ring, but the nature of the base, acid, or $\mathrm{NaBH}_{4}$ showed a major impact on this reaction. The typical class of the $\mathrm{C}-\mathrm{N}$ coupling reaction catalyzed by a $\mathrm{COOH}$-functionalized $\mathrm{GO}$ was also demonstrated under different temperatures. This catalyst showed very good stability under acidic and oxidizing catalytic reaction conditions. This approach has been proven to be efficient in synthesizing biologically active compounds.

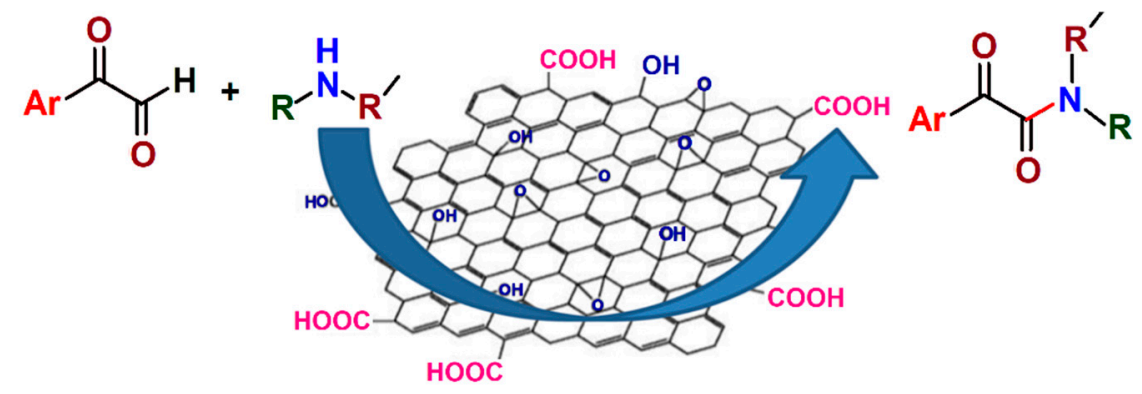

Scheme 4. C-N coupling of aldehydes with amines in the presence of GO through the cross-dehydrogenative coupling (CDC) pathway. From Majumdar et al. [78]. Reprinted with permission from [78]. The American Chemical Society, 2017.

\subsection{Dehydrogenative C-C Coupling Reaction}

Coupling reactions that allow for catalytic dehydrogenative $\mathrm{C}-\mathrm{C}$ bond formation have been accomplished using GO catalyst [79] to afford bi-aryl motifs, which are extensively present in pharmaceuticals, natural products, etc. The derivatives of 1,3,5-trialkoxybenzene underwent homo-coupling reaction in the presence of GO to afford high yields (70-86\%) (Scheme 5), whereas 1,2,4-trimethoxybenzene gave a 35\% product yield, because of inconsistent electronic effects exerted by the $-\mathrm{OCH}_{3}$ groups. The -naphthol derivatives also produced dimerized products in good yields $(71-80 \%)$, but steric effects arising from alkyl/alkoxy groups at the 2-position in naphthyl derivatives yielded low amounts (27-53\%) of their desired homo-coupling products. Apart from this, cross-dehydrogenative $\mathrm{C}-\mathrm{C}$ bond formation was achieved upon the reaction of naphthalene substituents with 1,3,5-trimethoxybenzene and the yield of coupling products was in the range of $34-77 \%$. This approach permitted an easy, simple, robust scale-up to the gram-scale, and it did not require any other additives. Surprisingly, other carbon allotropes were inactive during this reaction. The authors proposed that the unpaired electrons of GO were major contributors in determining the catalytic activity. 


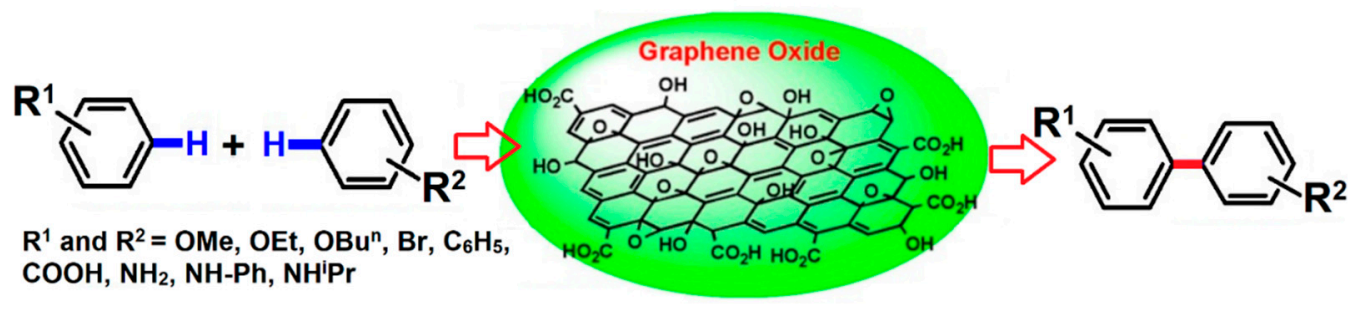

Scheme 5. C-C coupling catalyzed by a GO catalyst. From Fang et al. [79]. Reprinted with permission from [79]. Wiley Online Library, 2018.

$\mathrm{N}$-doped reduced graphene oxide (N-RGO) serves as an efficient metal-free catalyst toward the hydrogenation of 4-nitrophenol (4-NP), as shown in Scheme 6 [80]. Fabrication of a series of N-RGO meshes was achieved through the etching of 3-5 nm sized nanopores with doping of $\mathrm{N}$-dopants. They exhibited a high activity, which is comparable to metal nanoparticles [81], and they followed a pseudo-first order pathway with a $k$ value of $1.0 \mathrm{~s}^{-1} \mathrm{~g}^{-1} \mathrm{~L}$. The obtained value was 14-, and 26-fold more efficacious in comparison to N-doped graphene [82], and surface-modified RGO without nitrogen dopant, respectively. These catalysts showed good performance in their activities up to 12 cycles, indicating better reusability. They also exhibited poison resistance compared to N-RGO sheets [83]. Their catalytic activity was slightly decreased as a result of losing active sites through the adsorption of the 4 -aminophenol product by a $\pi-\pi$ stacking interaction. Likewise, Kong et al. [84] reported that $\mathrm{N}$-doped graphene catalyzed the reaction of 4-NP without the formation of by-products, giving a rate constant of 7.34-108 $\mathrm{mol} \mathrm{L}^{-1} \mathrm{~s}^{-1}$. As supported by theoretical studies, active sites could be generated from $\mathrm{C}$ atoms, which are next to the doped $\mathrm{N}$ atoms on $\mathrm{N}$-doped graphene (NG) surface; hence these NG meshes are a more useful candidate in the catalytic reduction of the nitro compound.

(a)

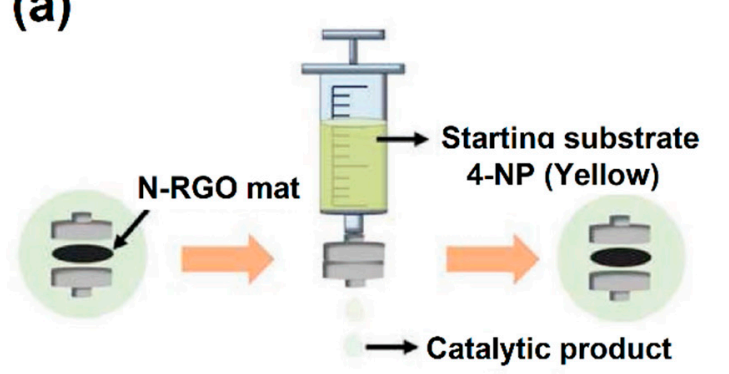

(b)

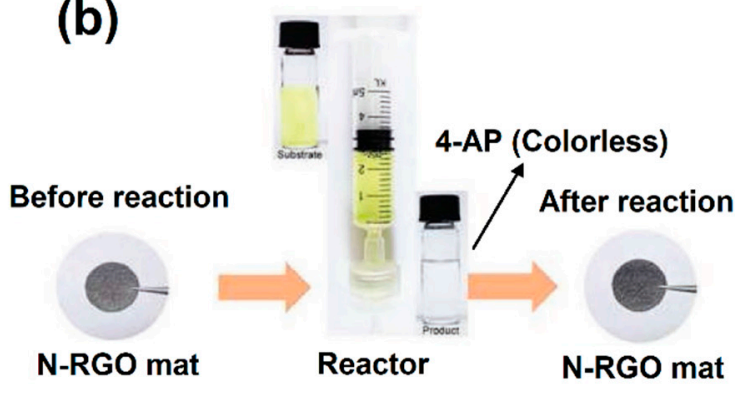

Scheme 6. (a) Schematic illustration of the catalytic process using N-doped reduced graphene oxide (N-RGO) meshes; (b) Photographs of the 4-NP before (left) and after (right) the addition of the N-RGO mat. From Kong et al. [84]. Reprinted with permission from [84]. The Royal Society of Chemistry, 2013.

Primo et al. reported that graphene (Gr) can be used to replace noble metals for the heterogeneous hydrogenation of carbon-carbon bond [85]. To support this claim, several alkene derivatives such as styrene, and -acetoxy- or -acetoxy-styrene underwent selective hydrogenation reaction in the presence of $\mathrm{Gr}$ to form their corresponding alkenes in 76.7, 82.1, and 9.1\%, respectively. Furthermore, the liquid phase hydrogenation of styrene, cyclooctene, and oleic acid took place selectively under batch conditions (Scheme 7). In these reactions, complete conversion was achieved at a long reaction time except for -acetoxy-styrene. A hydrogenation mechanism has been proposed for these systems, but the authors preferred theoretical calculations and surface techniques to understand the issues arising from these reactions. 


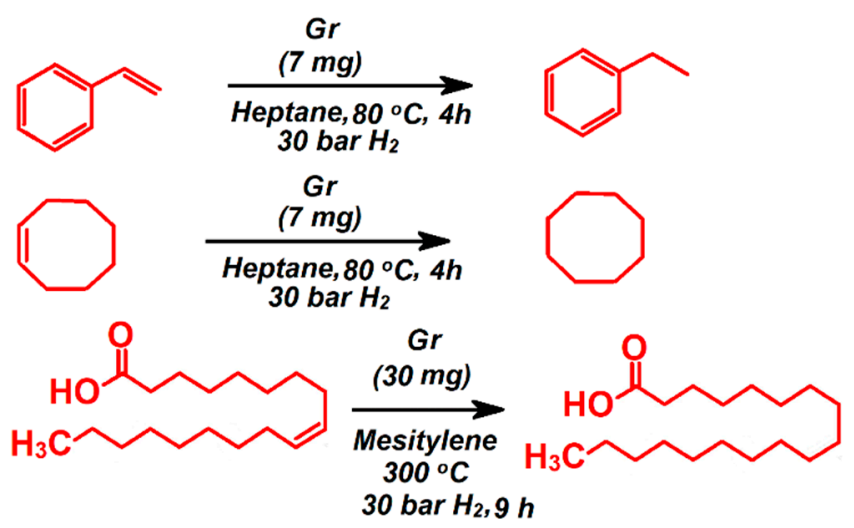

Scheme 7. Hydrogenation alkenes in the presence of Gr catalysts.

Recently, Zhang et al. have reported that GO catalyzed direct selective mono- and di-iodination of arenes or ketones using iodine at $120^{\circ} \mathrm{C}$ (Scheme 8) [86]. The mono-iodination reaction took place in $5 \mathrm{~min}-12 \mathrm{~h}$ catalyzed by GO $(20 \mathrm{mg})$ in a sealed tube containing $\mathrm{CH}_{3} \mathrm{NO}_{2}$. Through this approach, different mono-derivatives of arenes or ketones were prepared, with excellent yields (62-99\%). Using this protocol, different di-iodinated derivatives of arenes or ketones were synthesized in moderate to high yields (9-95\%) within 10-24 h. Encouraged by a successful gram-scale synthesis, this protocol yielded products selectively, with good to excellent yields. A mechanism has been proposed to link with unpaired electrons on GO, which played a vital role for this catalytic reaction. The reaction condition can inherently lead to simple technique because the use of additional compounds under conventional unpleasant chemical methods can be avoided.

\section{Monoiodination}

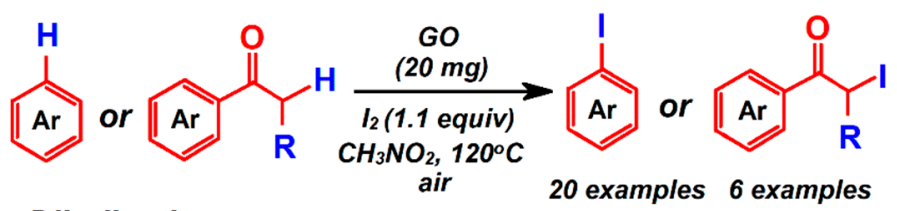

\section{Diiodination}

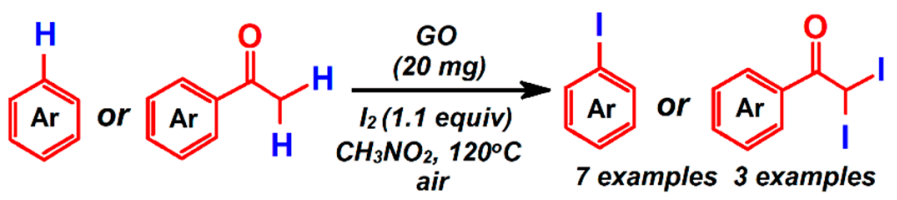

Scheme 8. GO-catalyzed iodination reaction of arenes with aromatic ketones.

Table 1 summarizes the utilization of GO catalyst in various organic transformations for the efficient synthesis of fine chemicals with the scope of opportunities in green chemistry for industrial applications. 
Table 1. Summary of the catalytic performance of GO-based catalysts.

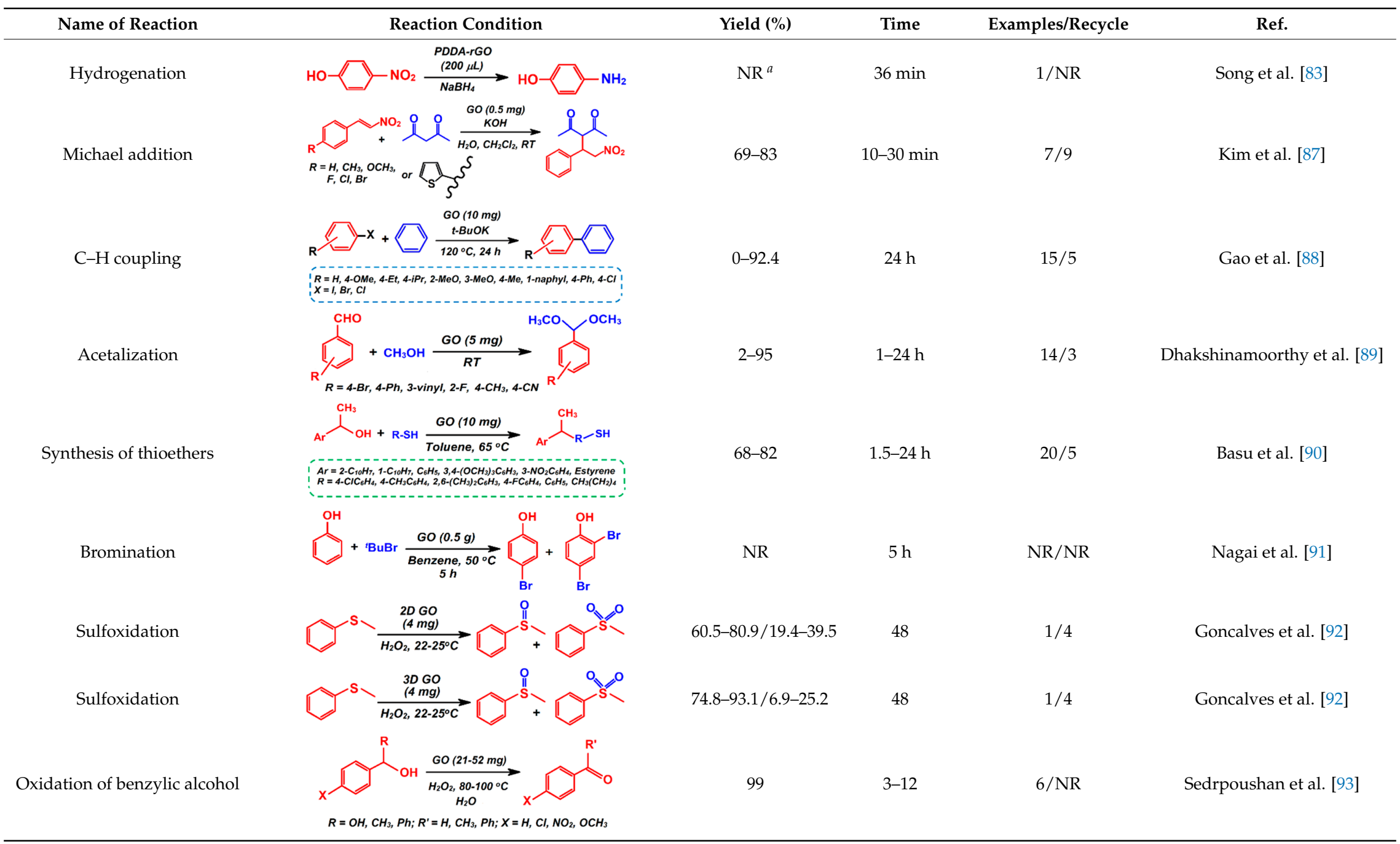


Table 1. Cont.

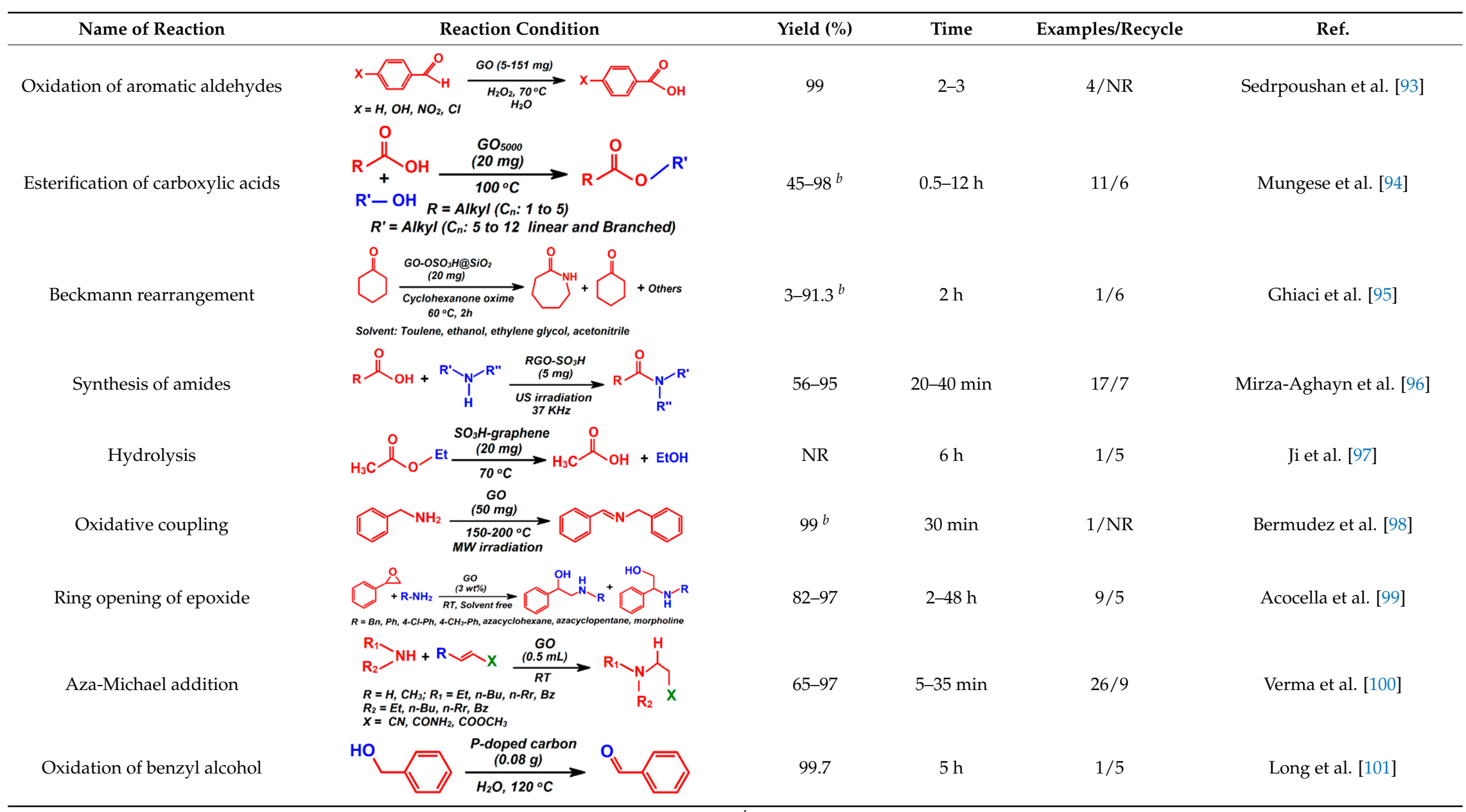




\section{Graphitic Carbon Nitride Nanocomposites for Catalysis}

A visible-light-responsive graphitic carbon nitride $(\mathrm{GCN})$ as a fascinating two dimensional (2D) conjugated and C- and N-atoms layered polymer, having impressive characteristics [102-106], has drawn increasing attention to its potential applications in catalysis and energy storage [107-112]. By taking advantages of their unique physical and chemical characteristics, including high surface area, excellent electrical conductivity, strong mechanical strength, unparalleled thermal conductivity, ease of functionalization, etc. these nanomaterials are often considered as a good candidate in photocatalytic and organic reactions [113,114]. From an environmental point of view, reactions involving oxygen or $\mathrm{H}_{2} \mathrm{O}_{2}$ as a renewable feedstock, and that are environmentally benign, with water as a byproduct, will be a more desirable $[112,113]$. Since triazine or tri-s-triazine-based crystalline bulk GCN having alternating $\mathrm{sp}^{2}$ hybrid $\mathrm{C}$ and $\mathrm{N}$ atoms exhibit a bandgap of $\sim 2.7 \mathrm{eV}$, they can be used for $\mathrm{C}-\mathrm{C}$ bond cleavage under photolysis [115]. On the other hand, the GCN is mainly restricted to electrochemical-related applications, due to its inherent low electronic conductivity and low surface area. However, after doping with heteroatoms like S, B, O, and P, the GCN substrate turns out to behave as a highly efficient and photostable organic photocatalyst $[116,117]$. The annual collections of number of papers dealing with the application of graphene derivatives in organic synthesis are shown in Figure 2.

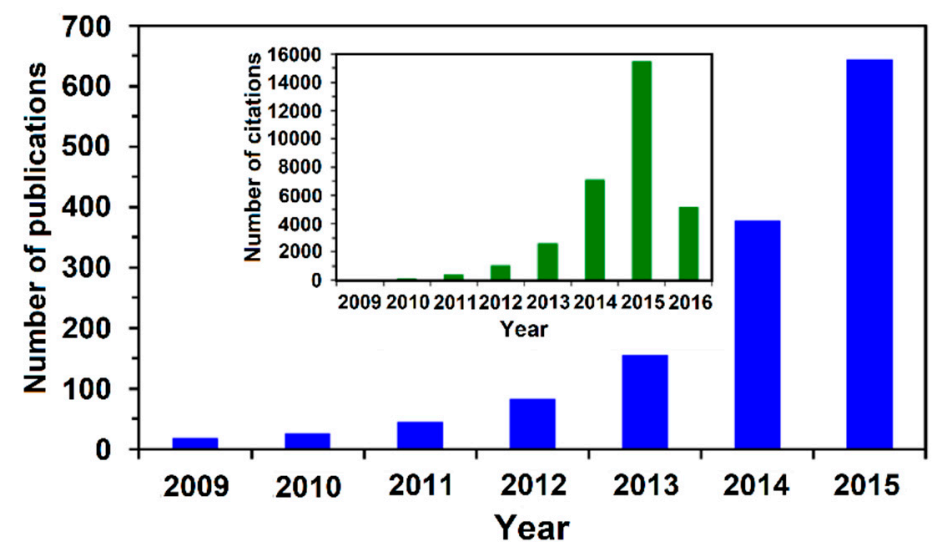

Figure 2. Annual number of publications containing the word "graphitic carbon nitride", "g- $\mathrm{C}_{3} \mathrm{~N}_{4}$ ", and "photocatalysis". Inset graph shows the journal citations since 2009. Adopted from Institute for Scientific Information (ISI) Web of Science, dated 20 April 2016. From Ong et al. [108]. Reprinted with permission from [108]. The American Chemical Society, 2012.

Nitrogen-rich organic precursors including cyanamide (CA) [117], dicyandiamide (DCA) [118], urea (U) [119], thiourea (TU) [120], ammonium thiocyanate (ATC) [121], melamine (MA) [122], and hexamethylenetetramine (HMT) [123] can be easily prepared through the thermal condensation at $500-600{ }^{\circ} \mathrm{C}$ in air or inert atmosphere. This review encompasses the synthesis and functionalization of GCN by incorporating organic heteroatoms or surface functional groups that prompt their place in a wide range of potential uses. In line with the focus of this review, we mainly highlight several nanosized metal-free and non-metal doped g-GCN catalysts. The following schematic diagram illustrates the fabrication of ultrathin GCN nanosheets through nitrogen-rich precursors in the different methods (Scheme 9). 


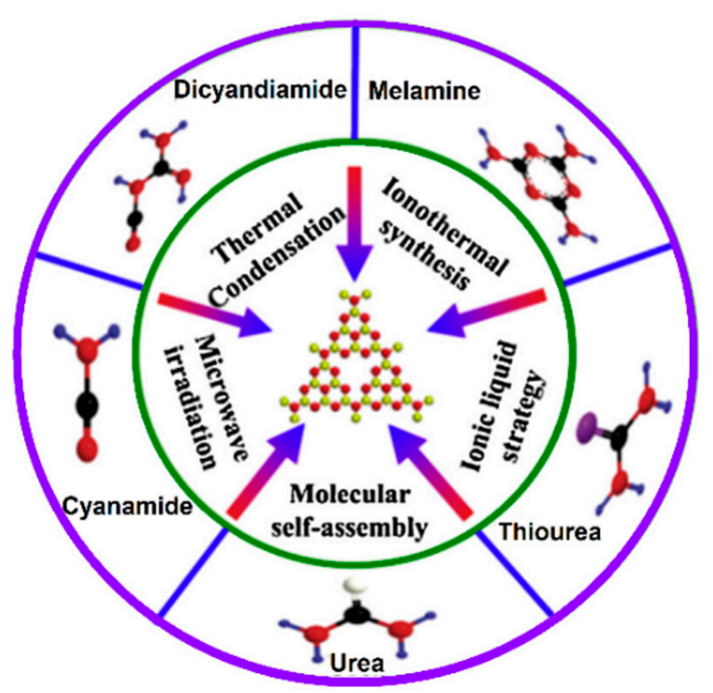

Scheme 9. Schematic representation for the fabrication of GCN using various precursors. From Wen et al. [123]. Reprinted with permission from [123]. Elsevier, 2017.

The metal-free catalyst also was invoked for many well-known organic reactions, including Knoevenagel condensation [124], cycloaddition [125], dehydrochlorination [126], transesterification [127], catalytic oxidation of cyclic olefins [128], and so forth. Besides, the industrial effluents contain several organic and inorganic pollutants which are acutely toxic and difficult for biodegradation [129]. However, these contaminants are genotoxic and they may disrupt endocrine systems even at trace level of concentrations, and hence the human health is at the high risk. De-colorization or complete mineralization is difficult because of the complex structure of the dyes and high recalcitrance to its degradation. Major studies have been carried out to develop new fascinating metal-free materials for dye removal. For example, rhodamine $\mathrm{B}\left(\mathrm{RhB}: \mathrm{C}_{28} \mathrm{H}_{31} \mathrm{~N}_{2} \mathrm{O}_{3} \mathrm{Cl}\right.$ ) and methylene blue ( $\mathrm{MB}: \mathrm{C}_{16} \mathrm{H}_{18} \mathrm{~N}_{3} \mathrm{SCl}$ ) dyes are highly detrimental to the ecosystem and thus, pose menace to the animals and human beings [130]. Luo et al. [131] have investigated the ordered mesoporous GCN for the photocatalytic degradation of $\mathrm{RhB}$, owing to its unique semiconductor band structure, excellent chemical, temperature stability, surface area $\left(\mathrm{S}_{\mathrm{BET}}=279.3 \mathrm{~m}^{2} \mathrm{~g}^{-1}\right)$ and pore volume $\left(\mathrm{V}_{\text {pore }}=0.38 \mathrm{~cm}^{3} \mathrm{~g}^{-1}\right)$. These prompted properties may enhance its charge carrier recombination, electron-hole separation, and performance. This catalyst degraded the RhB completely within $50 \mathrm{~min}$ with a $k$ value of $7.6 \times 10^{-2} \mathrm{~min}^{-1}$, which is larger by 16 -fold than that of the bulk g- $\mathrm{C}_{3} \mathrm{~N}_{4}$ (hereafter denoted as $\mathrm{BCN}$ ). Likewise, the fabricated inorganic salt-assisted GCN nanomaterials showed its highest catalytic activity with a $k$ value of $0.167 \mathrm{~min}^{-1}$ which is about 4.5 faster than that of BCN [132]. Other catalysts such as various phosphorus doped GCN, were also active with a $k$ value of $3.679 \times 10^{-2}, 8.27 \times 10^{-2}, 9.856 \times 10^{-2}$, $6.493 \times 10^{-2}, 4.495 \times 10^{-2}$ and $8.8 \times 10^{-4} \mathrm{~min}^{-1}$ for $0,0.5,1.0,1.5$, and $2.5 \% \mathrm{P}$ doping and without catalysts, respectively. In this reaction, the rate constant of $1 \% \mathrm{P}$ doping was about 2.7 times as large as that of BCN [133]. The reaction mechanism for the photocatalytic degradation of RhB by P-doped GCN catalysts is also proposed (Scheme 10). 


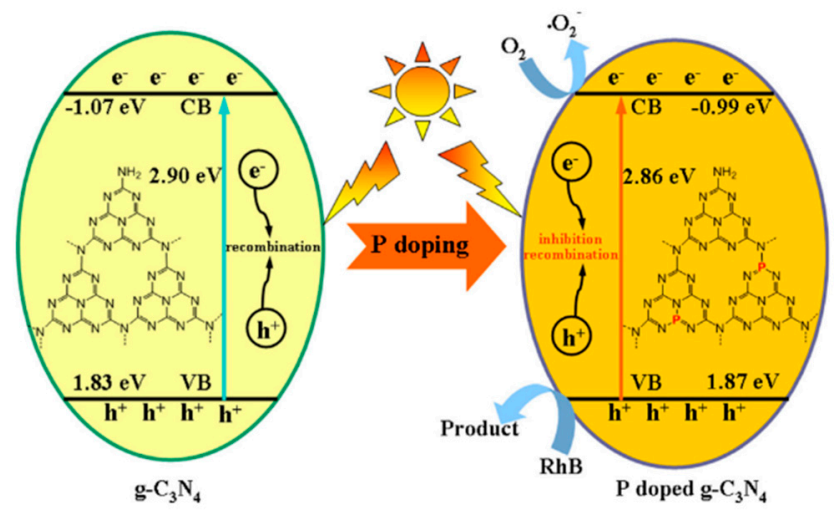

Scheme 10. Degradation pathway for RhB by P-doped GCN photocatalyst. From Chai et al. [133]. Reprinted with permission from [133]. Elsevier, 2017.

The photocatalytic degradation of organic pollutants is summarized in Figure 3a, containing the distribution estimated for the different categories of materials and modifications.

(a)

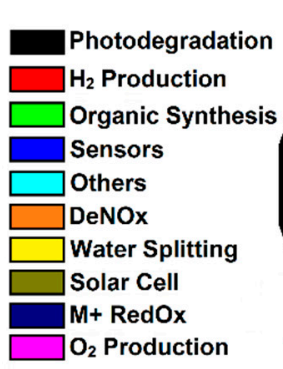

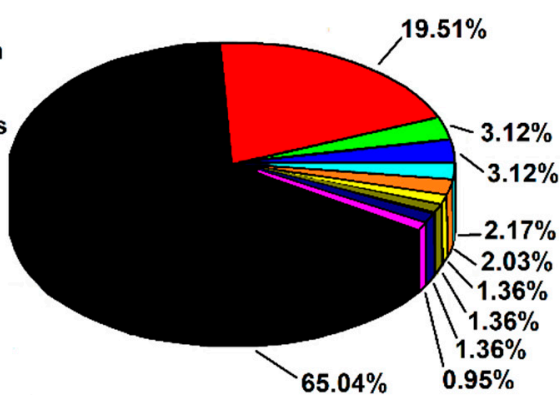

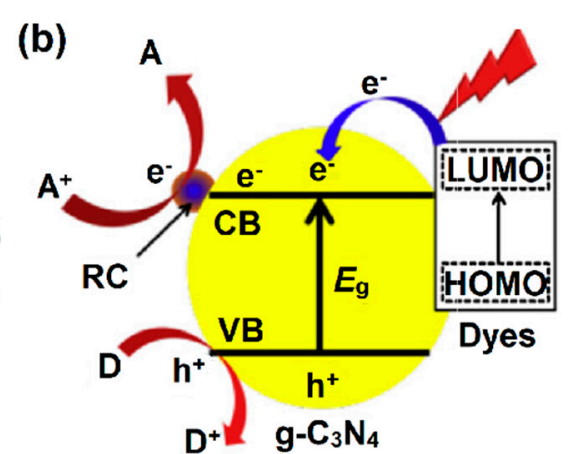

Figure 3. (a) Pie chart distribution of various photoactive applications of GCN (From Masih et al. [104]. Reprinted with permission from [104]. Elsevier, 2017), and (b) mechanism for GCN photocatalyst sensitized by organic dyes (From Wen et al. [123]. Reprinted with permission from [123]. Elsevier, 2017).

The corresponding mechanism shown in Figure $3 b$, has been widely applied in enhancing the visible-light absorbance of GCN-based metal-free catalysts, which will be thoroughly discussed in this section. Briefly:

$$
\begin{aligned}
& \mathrm{GCN}+\mathrm{h} v \rightarrow \mathrm{GCN} \times \mathrm{e}^{-} \mathrm{CB}+\mathrm{h}^{+}{ }_{\mathrm{VB}} \\
& \mathrm{h}^{+} \mathrm{VB}+\mathrm{H}_{2} \mathrm{O} \rightarrow{ }^{\bullet} \mathrm{OH}+\mathrm{H}^{+} \\
& \mathrm{O}_{2}+\mathrm{e}^{-} \mathrm{CB}^{-} \rightarrow \mathrm{O}_{2}{ }^{\bullet-} \\
& \mathrm{O}_{2}^{\bullet-}+\mathrm{H}^{+} \rightarrow \mathrm{HO}_{2}^{\bullet} \\
& \mathrm{HO}_{2}{ }^{\bullet}+\mathrm{HO}_{2}{ }^{\bullet} \rightarrow \mathrm{H}_{2} \mathrm{O}_{2}+\mathrm{O}_{2} \\
& \mathrm{O}_{2}^{\bullet-}+\mathrm{HO}_{2}{ }^{\bullet} \rightarrow \mathrm{O}_{2}+\mathrm{HO}_{2}{ }^{-} \\
& \mathrm{HO}_{2}{ }^{-}+\mathrm{H}^{+} \rightarrow \mathrm{H}_{2} \mathrm{O}_{2} \\
& \mathrm{H}_{2} \mathrm{O}_{2}+\mathrm{h} v \rightarrow 2^{\bullet} \mathrm{OH} \\
& \mathrm{H}_{2} \mathrm{O}_{2}+\mathrm{O}_{2}{ }^{\bullet-} \rightarrow \bullet \bullet \mathrm{OH}+\mathrm{OH}^{-}+\mathrm{O}_{2} \\
& \mathrm{H}_{2} \mathrm{O}_{2}+\mathrm{e}^{-}{ }_{\mathrm{CB}}^{-} \rightarrow \bullet \mathrm{OH}+\mathrm{OH}^{-}
\end{aligned}
$$

Organic dye $+{ }^{\bullet} \mathrm{OH} \rightarrow$ Degradation products

Organic dye $+\mathrm{GCN}\left(\mathrm{h}^{+}\right) \rightarrow$ Degradation products 


$$
\text { Organic dye }+\mathrm{GCN}\left(\mathrm{e}^{-}\right) \rightarrow \text { Degradation products }
$$

In addition to $\mathrm{H}_{2} \mathrm{O}_{2}$, a variety of active radicals, including $\mathrm{O}_{2}{ }^{\bullet-}, \bullet \mathrm{OH}$, and $\mathrm{HO}_{2}{ }^{\bullet}$, have been invoked as the oxidants responsible for mineralization, and ${ }^{\bullet} \mathrm{OH}$ is the most likely candidate (Equation (11)). Direct oxidation of carboxylic acids by photoexcited holes to generate $\mathrm{CO}_{2}$ has also been evidenced in Equation (12), termed the 'photo-Kolbe reaction'. Reductive pathways involving photoexcited electrons (Equation (13)) are considered unimportant in dye degradation; however, the thermodynamic requirements for GCN metal-free photocatalysts dictate the oxidation potential of

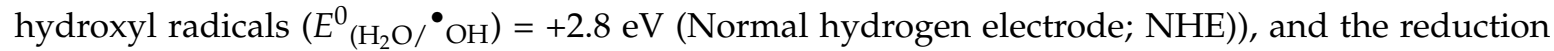
potential of superoxide radicals $\left(E^{0}\left(\mathrm{O}_{2} / \mathrm{O}_{2} \bullet-\right)=-0.3 \mathrm{eV}(\mathrm{NHE})\right)$ lie well within the band gap between the valance band (VB) and conduction band (CB) [46-48].

In another study, Zhao et al. [134] studied the photocatalytic reduction of RhB with the help of nanoporous-tube like GCN composites (PTCN) upon the irradiation of visible light. It was observed that within 40 min nearly $90 \%$ of the RhB was photodegraded with a $\mathrm{k}$ value of $4.491 \times 10^{-2} \mathrm{~min}^{-1}$, which is 8.16-, 3.09-, and 1.48-fold more active compared to $\mathrm{BCN}$, tubular $\mathrm{GCN}$, and tubular $\mathrm{GCN}^{-} \mathrm{SiO}_{2}$, respectively. The edge effect of the pores and unique tubular structures led to the enhancement of its photocatalytic efficiency. Furthermore, a trapping experiment studies revealed the formation of $\mathrm{O}_{2}{ }^{\bullet-}$ and $\mathrm{h}^{+}$to support the knowledge of free radical production mechanism (Scheme 11).

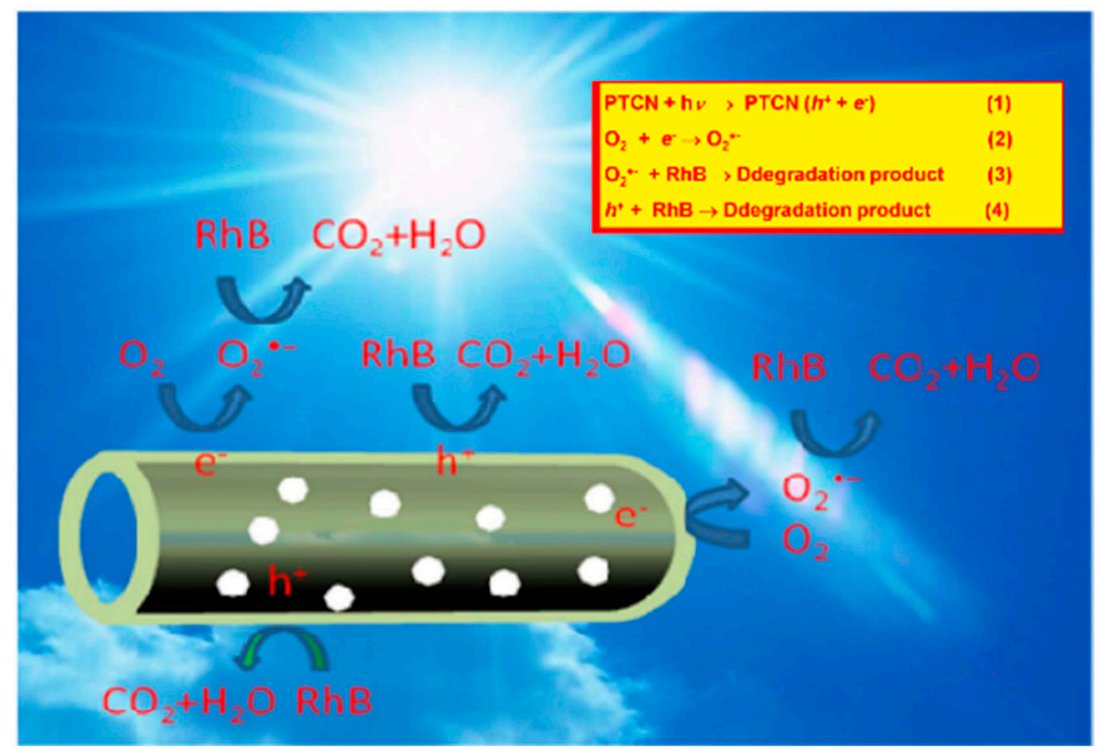

Scheme 11. Possible photocatalytic degradation mechanism in PTCN. From Zhao et al. [134]. Reprinted with permission from [134]. IOP publishing Ltd., 2017.

Yang et al. [135] have reported the application of mesoporous graphitic carbon nitride (mpg- $\left.\mathrm{C}_{3} \mathrm{~N}_{4}\right)$ catalyst, which was obtained using guanidine hydrochloride, dicyandiamide, and urea as precursors and $\mathrm{SiO}_{2}$ as a template, in a Friedel-Crafts acylation of arenes. This catalyst underwent good catalytic performance for the Friedel-Crafts acylation of arenes with hexanoyl chloride to afford a final product conversion of $89 \%$ and $75 \%$ at $90{ }^{\circ} \mathrm{C}$ and $27{ }^{\circ} \mathrm{C}$, respectively. It could retain at least $80 \%$ activity, and therefore, it was reusable.

In 2016, Xu et al. used a series of mesoporous g-CN catalysts in Knoevenagel condensation and transesterification reactions [136]. Assisted by a detemplation approach, a cheap precursor dicyandiamide was used to prepare a mesoporous carbon nitride catalyst through a nanocasting method. Upon eliminating silica template using alkaline solutions, the ordered mesostructures can be retained in the obtained materials. This catalyst proceeded a well base-catalyzed Knoevenagel condensation with a remarkable catalytic conversion of $37-96 \%$ along with a selectivity of $80-98 \%$ to yield the corresponding products at $37-92 \%$. In addition, this catalyst demonstrated its excellent 
activity in the transesterification of ethylene carbon (EC) and $\mathrm{CH}_{3} \mathrm{OH}$ to afford its $91.3 \%$ conversion and $99.3 \%$ selectivity to dimethyl carbonate at $160{ }^{\circ} \mathrm{C}$. It was found that their efficiencies are higher than that of the catalysts templated by conventional HF. The authors recycled the catalytic solution up to four times without minimal loss of its activity.

To overcome the drawbacks including coupling with doping heteroatoms, joining with semiconductors, or fabricating new nanocomposites for active GCN catalyst, several strategies have been developed. For instance, Zhao et al. [137] investigated the catalytic activity of highly-ordered mesoporous GCN toward the ethylbenzene dehydrogenation under $\mathrm{O}_{2}$, as well as steam-free reaction conditions. Catalysts having a large surface area $\left(971-1124 \mathrm{~m}^{2} \mathrm{~g}^{-1}\right)$, pore volume $\left(1.31-1.79 \mathrm{~cm}^{3} \mathrm{~g}^{-1}\right)$, and rich $\mathrm{N}$ content $(9.3-23 \mathrm{wt} \%)$ were prepared through a nanocasting route upon the use of SBA-15 and HMT as a template and precursor, respectively (Scheme 12). It was found that several factors including temperature and precursors become a dominant parameter in determining pore volume, specific surface area, and $\mathrm{N}$ content of these catalysts. Upon the pyrolysis temperature of $750{ }^{\circ} \mathrm{C}$, the catalyst displayed excellent catalytic activity (11.6\% of product yield with $93.6 \%$ selectivity) over other carbon materials such as classical mesoporous carbon and mesoporous GCN, and nanodiamond (ND) owing to their presence of abundant $\mathrm{C}=\mathrm{O}$ functional group, defect/edge characteristics, smaller size, ultrahigh surface area and pore volume. Different mesophore CNs containing different textural characteristics using various templates could also be prepared under different conditions.

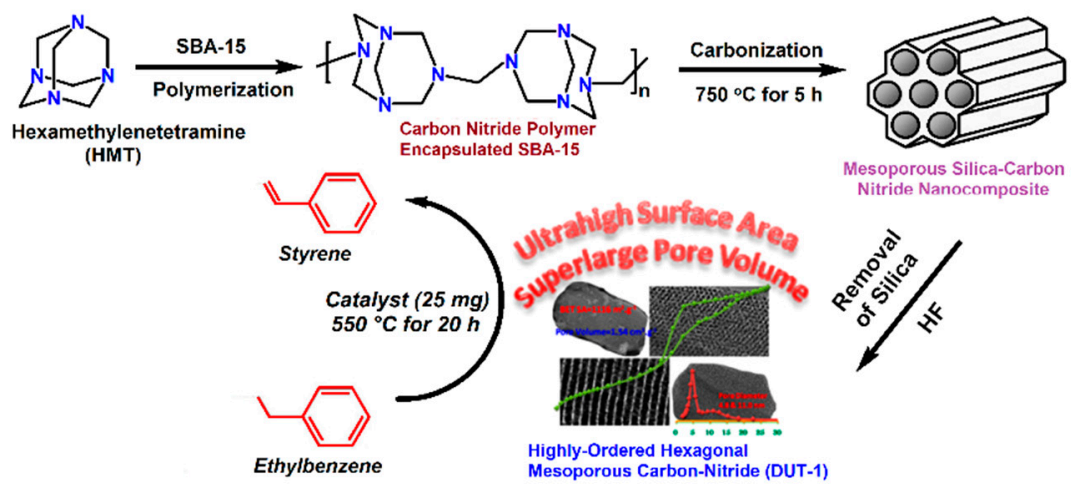

Scheme 12. Schematic illustration of the synthesis of highly ordered mesoporous GCN nanocomposite, and its catalytic applications. From Zhao et al. [137]. Reprinted with permission from [137]. The American Chemical Society, 2014.

Boron-doped GCN nanomaterials have drawn a great attention as a metal-free, solvent-free, and an ecofriendly catalyst $[138,139]$. These studies focused on describing the metal-free active sites that are responsible for the catalytic performances of various reactions. It has been shown that various defects such as carbon vacancies, holes, and edge effects, chemical doping of non-metals like B, S, and $\mathrm{P}$, and heir functionalities on the GCN layers influenced their roles in diverse catalytic reactions [140]. Apart from this, the contribution of adsorbing substrates and reagents, and charge transfer toward their catalytic performances was also discussed.

Jiang, et al. have studied the photocatalytic activity for RhB and tetracycline (TC) degradation using hexagonal boron nitride-decorated GCN nanocomposites, which was prepared by in situ growing process [141]. As this catalyst possessed a large surface area and fast electron transfer characteristics, it increased photoexcited holes transfer and promoted the charge separation. In this catalyst, hexagonal boron nitride behaved as a promoter for photoexcited holes transfer. Catalytic studies revealed that this nanocomposite showed a 7.3 and 11.8 times higher catalytic activity for RhB degradation, and 2.3 and 60.3 times higher catalytic activity for TC degradation compared to GCN and hexagonal boron nitride (h-BN), respectively. The plausible reaction pathway for the photodegradation of $\mathrm{RhB}$ over visible light responsive to $\mathrm{h}-\mathrm{BN} / \mathrm{g}-\mathrm{C}_{3} \mathrm{~N}_{4}$ is shown in Scheme 13. 


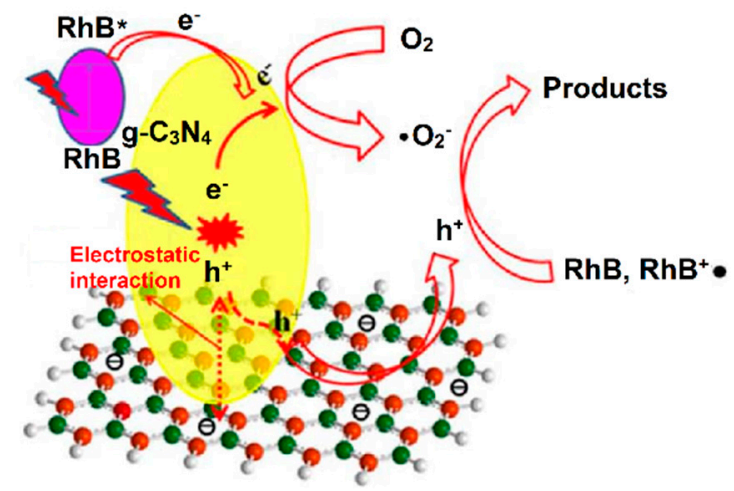

Scheme 13. Plausible mechanism of the RhB photocatalytic degradation. Jiang et al. [141]. Reprinted with permission from [141]. Elsevier, 2018.

To enhance surface reaction activity of the photocatalysts, various elements such as boron and nitrogen have been successfully incorporated into the structure of GCN. Yan et al. [142] improved significantly the photocatalytic performance of B-doped GCN catalyst by loading of the boron element. The B-doped GCN catalyst was obtained upon heating the reaction mixture of MA and boron oxide (BO) at $727^{\circ} \mathrm{C}$ for $2 \mathrm{~h}$ (Scheme 14a). The band gap of B-doped GCN was found to be $2.66 \mathrm{eV}$ in comparison to bare GCN $(2.7 \mathrm{eV})$. Several factors, including their unique photophysical and chemical properties, dye adsorption, a decrease in band gap $(0.04 \mathrm{eV})$, and efficient light absorption are beneficial for the photodegradation of RhB. Catalytic studies on the degradation of $\mathrm{RhB}$ revealed that this nanocomposite underwent the first-order reaction pathway, giving a $\mathrm{k}$ value of $0.199 \mathrm{~min}^{-1}$, which is two-folds more active compared to GCN $\left(\mathrm{k}=6.5 \times 10^{-2} \mathrm{~min}^{-1}\right)$. This process was ascribed to the photogenerated hole oxidation as evidenced by electron paramagnetic resonance (EPR) analysis and several comparison experiments. However, in the case of photodegrading methyl orange (MO), both catalysts obtained at $580{ }^{\circ} \mathrm{C}$ and $600{ }^{\circ} \mathrm{C}$ showed the similar rate constant $\left(4.0 \times 10^{-2} \mathrm{~min}^{-1}\right)$, which was ascribed to the overall reaction. The overall mechanistic pathways for the photodegradation of $\mathrm{RhB}$ and MO by this catalyst are described (Scheme 14b).

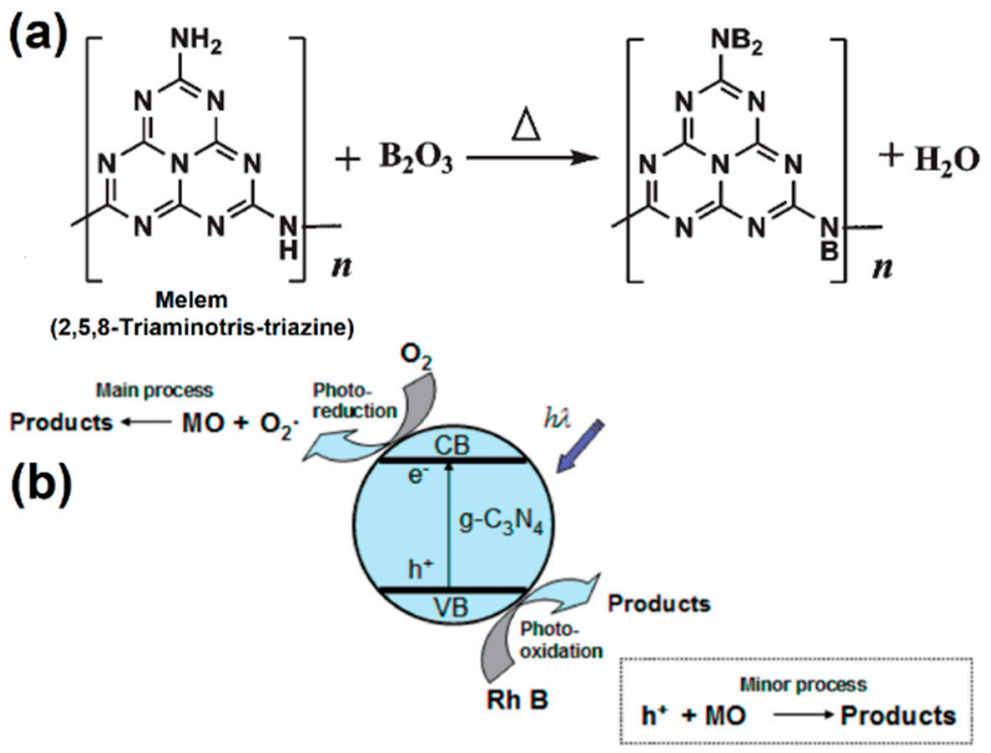

Scheme 14. (a) Preparation route of B-doped GCN and (b) photocatalytic degradation mechanism of MO and RhB over B-doped GCN. Yan et al. [142]. Reproduced with permission from [142]. The American Chemical Society, 2010. 
Hu et al. [143] prepared outstanding visible light active oxygen-functionalized sulphur-, and phosphorus-co-doped GCN nanorods under hydrothermal condition. The use of S- and P-codoping led not only to inhibit the crystal growth of GCN, but also enhanced the efficiency of the separation of the photogenerated electrons and holes. In this system, functional oxygen atoms play key factors in enhancing the GCN adsorption ability and the production of photogenerated holes via capture of photogenerated electrons for the catalytic activity of $\mathrm{RhB}$ photodegradation under anoxic conditions. Under optimized conditions, this catalyst showed the RhB photodegradation rate constant of $2.6 \times 10^{-2} \mathrm{~min}^{-1}$, which is 13- and 2-fold more active compared with $\mathrm{CN}$ and P-SN, respectively.

For enhancing the catalytic performance of visible light responsive catalyst, Dang et al. [144] fabricated a core-shell heterojunction using $\mathrm{C}_{3} \mathrm{~N}_{4}$ nanocomposite enwrapped with $\alpha$-sulfur $\left(-\mathrm{S}_{\mathrm{C}} \mathrm{C}_{3} \mathrm{~N}_{4}\right)$ by a self-assembly method. Upon changing the amount of ultra-thin $\mathrm{C}_{3} \mathrm{~N}_{4}$ nanosheet which acts as a charge transporter, the photocatalytic activity of this catalyst can be tuned. In this system, the GCN nanosheets alone act as a visible-light-driven photocatalyst (Scheme 15). The nanocomposite containing $35 \%$ GCN nanosheets showed 6.72 times higher RhB photodegradation rate in comparison with -S owing to the effective separation of the photogenerated holes and electrons. Upon the modification of GCN with carbon-based nanostructures, an enhanced absorption efficiency from visible-to-infrared (IR) light could be achieved with the fast transfer of photogenerated carriers.

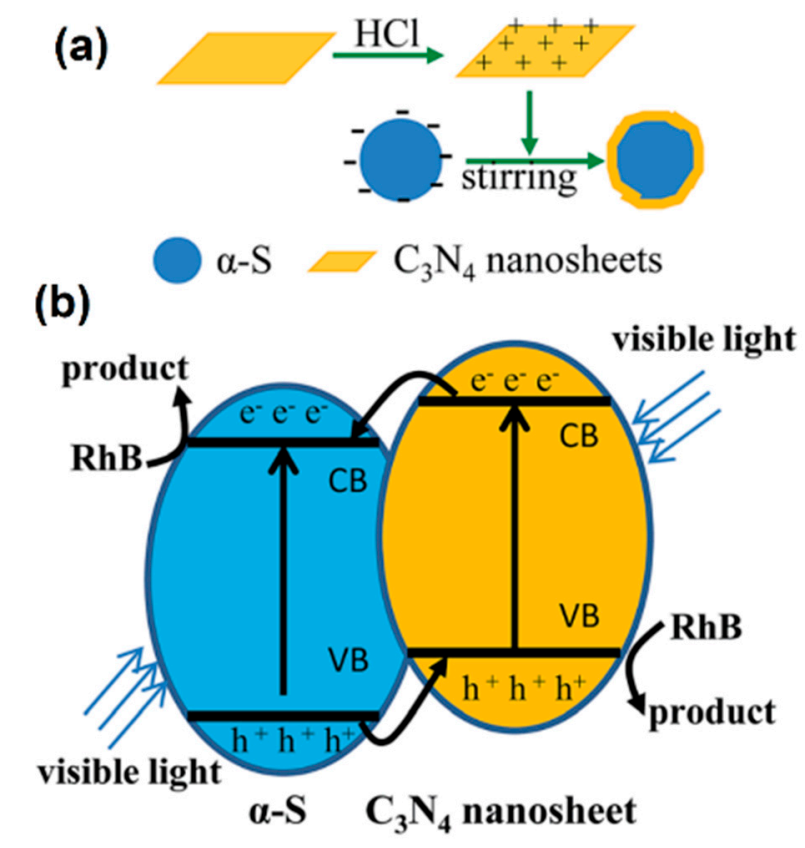

Scheme 15. (a) Scheme illustrates the synthesis of $-S @ C_{3} N_{4}$ nanocomposites and (b) its mechanistic pathway for the catalytic activity. From Dang et al. [144]. Reprinted with permission from [144]. The Royal Society of Chemistry, 2015.

Producing the GCN with porous carbon structure can greatly enhance the number of active chemical sites, which could increase the catalytic activity upon the irradiation of visible light. For example, the fabrication of a photocatalyst GO-modified GCN (GO/GCN) via a sonochemical approach was achieved [145]. It was observed that this hybrid photocatalyst underwent pseudo-first-order pathway, giving a $k$ value of photocatalytic degradation for $\mathrm{RhB}$ to be 2.08 times with respect to the pristine GCN. Additionally, it displayed good stability after five consecutive experiments; the stability results are displayed in Figure 4a. However, the photocatalytic efficiency declined by only $1.5 \%$, as observed for GO/GCN, indicating its superior catalytic stability upon illumination by visible light. The RhB degradation reaction pathway is also illustrated (Figure 4b). Based on this mechanism, it was observed that degradation was highly dependent on the nature of electron-hole separation and electron transport. 

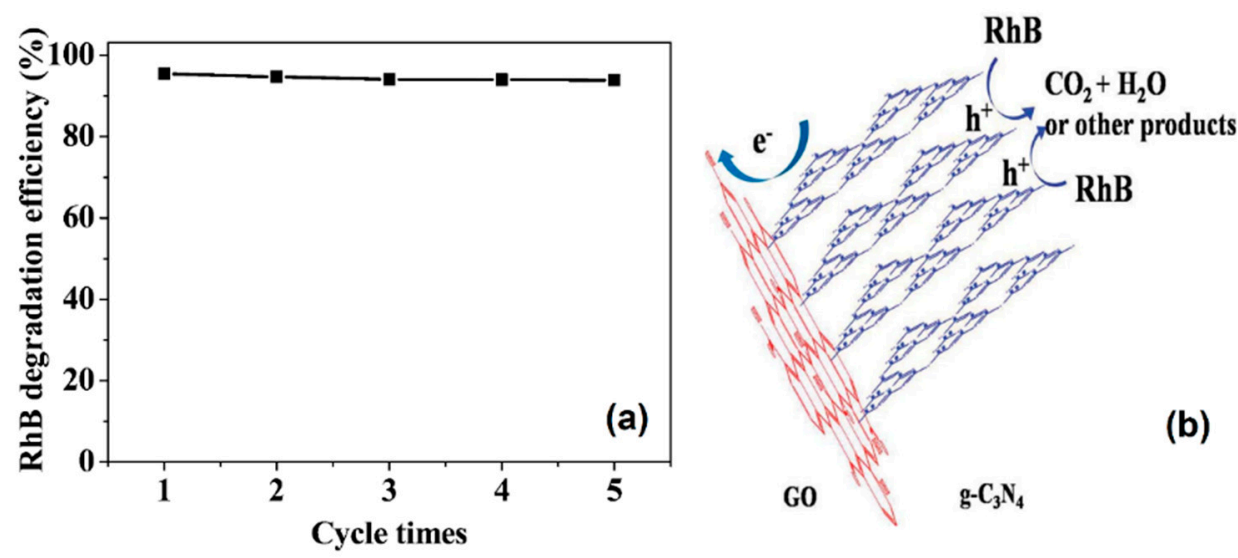

Figure 4. (a) RhB degradation efficiency and (b) Proposed mechanism of the catalytic degradation of RhB using GO/GCN hybrid catalyst under visible light illumination. From Liao et al. [145]. Reprinted with permission from [145]. The Royal Society of Chemistry, 2015.

Zhao et al. [146] assembled a 0.4-0.5 nm sized single layer GCN nanosheets (SL g- $\left.\mathrm{C}_{3} \mathrm{~N}_{4}\right)$ via an ultrasonic exfoliating protocol using a few layer graphitic- $\mathrm{C}_{3} \mathrm{~N}_{4}$ precursors, and applied it for the photocatalytic remediation of environmental pollutant $(\mathrm{RhB})$ in the water. Time-resolved emission and electrochemical studies revealed its high photogenerated charge lifetime, and enhanced the charge transfer capability, respectively. Upon visible light irradiation, SL GCN underwent photodegradation of $\mathrm{RhB}$, giving a rate constant of $1.96 \mathrm{~h}^{-1}$, which was 3.0-, 8.8-, 10.2-, 16.4-, 37.1- and 93.8-fold higher compared to GCN NS, CdS, bulk GCN, N-TiO $2, \mathrm{P} 25\left(\mathrm{TiO}_{2}\right.$; Degussa), and $\mathrm{BiVO}_{4}$, respectively. This catalyst promoted the recombination of photogenerated charge and electron transporter.

Apart from RhB, methylene blue (MB), crystal violet (CV), methyl orange (MO), acid red 18 (AR 18) and orange II are also classified as environmental pollutants whose break down products are potentially toxic, and carcinogenic to living organisms [147]. In 2009, Yan et al. [148] have prepared a visible light sensitive GCN catalyst to perform the catalytic photodegradation of MO in water. The use of nitrogen-doped- $\mathrm{TiO}_{2}, \mathrm{Ag}$ loading, and acid radical ions also promoted degradation of $\mathrm{MO}$ rate and the results were compared with that of MO degradation over the GCN. From these results, it was clearly observed that the photo-reduction pathway led by the photogenerated electrons resulted in high catalytic performance for MO photodegradation when using this catalyst.

Recently, $\mathrm{Xu}$ and co-workers [149] prepared $\sim 2 \mathrm{~nm}$ sized with larger active sites and pore volume containing porous $\mathrm{g}-\mathrm{C}_{3} \mathrm{~N}_{4}$ nanosheet (PCNS) through a template-free strategy in the absence of any reagents. Upon the illumination of visible-light, PCNS underwent the photodegradation of MB with pseudo-first order reaction, affording the apparent $\mathrm{k}$ value of $0.551 \mathrm{~h}^{-1}$, which is 6.4 - and 1.6-fold higher compared to that of BCN and PCN, respectively. The degradation of Acid Red 27 (AR 27), and bisphenol A (BPA) using this catalyst under photolysis also followed pseudo-first-order kinetics, affording the apparent $\mathrm{k}$, which is 4.0-, and 1.9-fold higher compared to BCN. Besides, PCNS showed a 3.7 times higher photocurrent intensity compared to $\mathrm{BCN}$. In addition, PCNS were able to kill Escherichia coli cells completely within $4 \mathrm{~h}$, but BCN killed only $77.1 \%$ of cells. The entire dye reduction pathway mechanism is clearly represented in Scheme 16. Considering their larger Brunauer-Emmett-Teller (BET) surface area, larger surface active sites, and high charge transfer and separation efficiency, visible light-responsive PCNS acts as an excellent candidate for the photocatalytic remediation of environmental pollutants. 


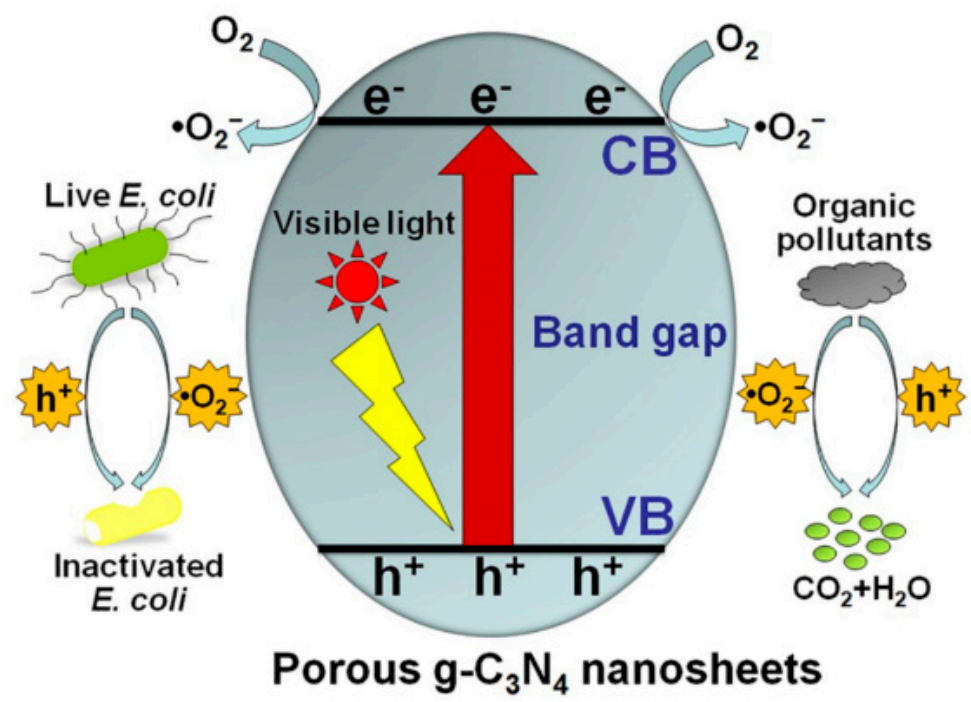

Scheme 16. Porous $g-\mathrm{C}_{3} \mathrm{~N}_{4}$ nanosheet (PCNS) catalyst showing the charge separation mechanism and catalytic pathways in the presence of visible light irradiation. Xu et al. [149]. Reprinted with permission from [149]. The American Chemical Society, 2017.

In 2017, Fan and coworkers [150] reported the catalytic activity of a visible light-responsive S-doped GCN porous catalyst (S-pg- $\mathrm{C}_{3} \mathrm{~N}_{4}$ ) for $\mathrm{RhB}$ degradation. This catalyst showed good adsorption and catalytic activity in comparison to bulk g- $\mathrm{C}_{3} \mathrm{~N}_{4}$ as a result of synergetic effects between S-doping and the structure of the catalyst. Recently, Panneri and co-workers [151] demonstrated a synthetic route for the synthesis of carbon-doped GCN (Scheme 17a) for effective tetracycline (TC) removal upon the illumination of visible light. During the template-free spray drying process, followed by thermal oxidation at $500{ }^{\circ} \mathrm{C}, \mathrm{g}-\mathrm{C}_{3} \mathrm{~N}_{4}$ nanosheets, which was obtained from the urea-thiourea (U-TU) mixture pyrolysis, was changed into microspheres. These two processes caused the formation of the minimized band gap and longer absorption range of visible region in the catalyst after the introduction of C-doping into the catalyst. This catalyst exhibited a higher percentage of adsorption and photodegradation of TC compared to BCN. The mechanistic pathway for the photocatalytic TC degradation using this catalyst is also demonstrated (Scheme 17b). This catalyst displayed a considerably high activity, even after five recycling rounds.
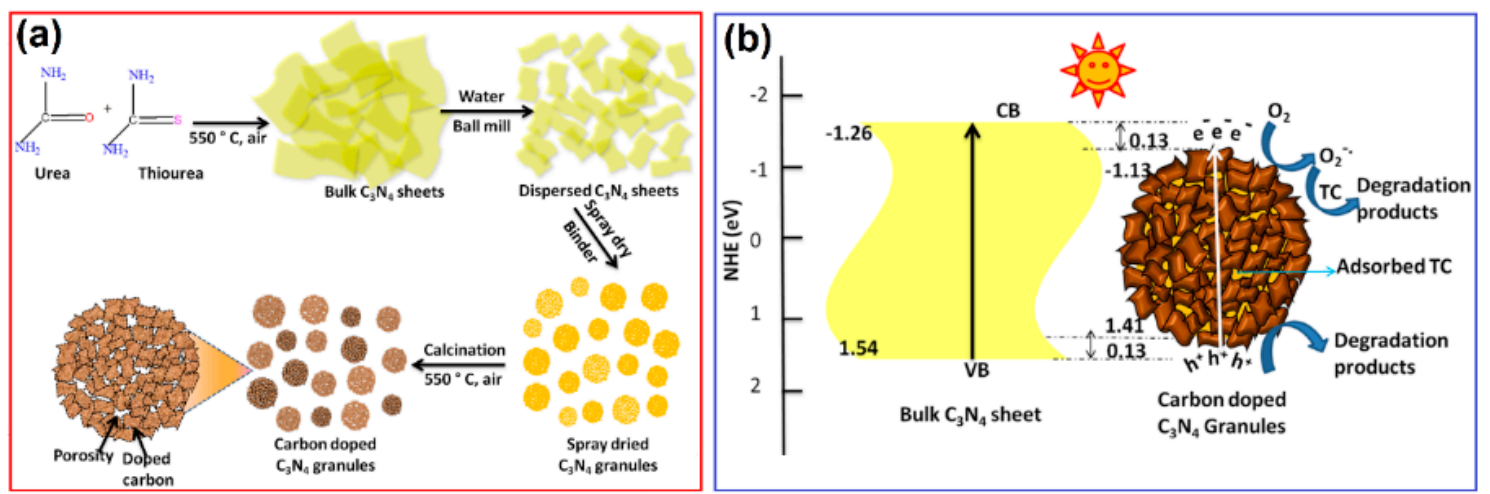

Scheme 17. (a) Scheme illustrates the generation of carbon doped on porous GCN and (b) the photocatalytic mechanism of TC degradation. Panneri et al. [151]. Reproduced with permission from [151]. The American Chemical Society, 2017. 
In another study, Zhang and coworkers [152] demonstrated the synthesis of S-, and O-co-doped GCN via the polymerization of melamine- and $\mathrm{H}_{2} \mathrm{O}_{2}$-bonded trithiocyanuric acid at room temperature (Scheme 18a). On comparison with pristine $\mathrm{g}-\mathrm{C}_{3} \mathrm{~N}_{4}$, this catalyst showed a 6-fold enhancement in the photocatalytic RhB degradation owing to its superior properties such as increasing visible light adsorption and decreasing its band gap (Scheme 18b). Computational studies proved that these dopants not only influenced strong highest occupied molecular orbital (HOMO) and lowest unoccupied molecular orbital (LUMO) delocalization but also increased more active sites to make the migration of photogenerated electron/hole pairs easier.
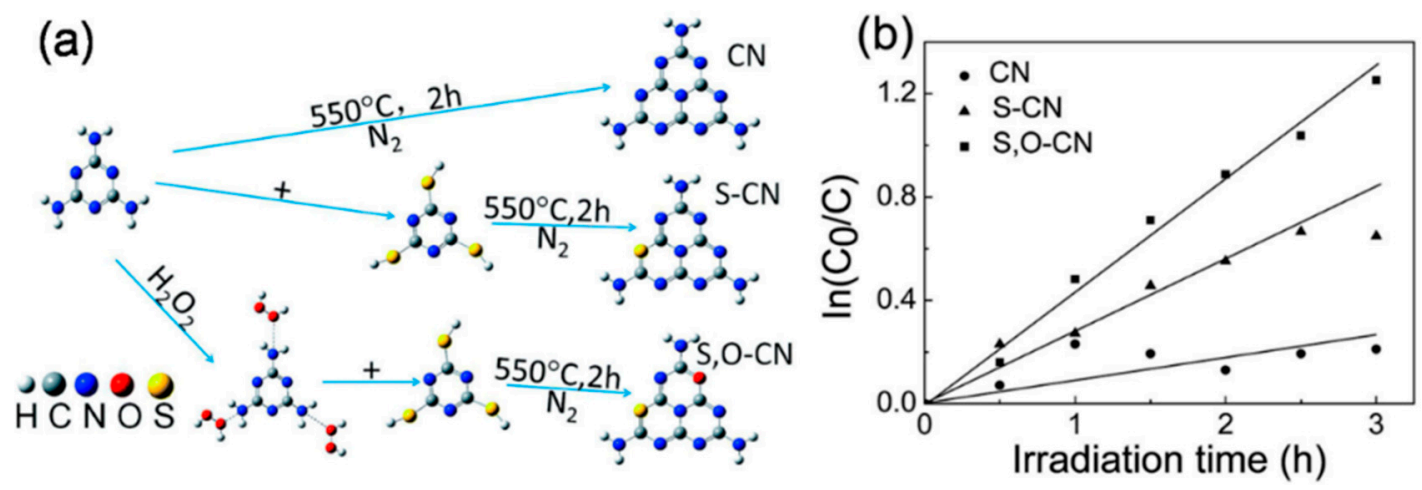

Scheme 18. (a) Synthetic routes, and (b) RhB photodegradation using S and O co-doped GCN. Zhang et al. [152]. Reprinted with permission from [152]. The Royal Society of Chemistry, 2017.

Yuan et al. [153] fabricated 3D porous thermally exfoliated GCN nanosheets by the reaction of few-layered nanosheets interconnected via $\mathrm{H}_{2} \mathrm{SO}_{4}$ intercalation, followed by heating the reaction mixture. Compared to bulk $\mathrm{C}_{3} \mathrm{~N}_{4}$, it exhibited a good performance in RhB photodegradation and followed a pseudo-first order pathway, yielding a rate constant of four times higher. This can be ascribed due to the availability of a number of active sites, longer carrier lifetime, and the shorter route of the carriers to the active sites. This catalyst displayed a considerably high activity, even after 11 rounds of recycling.

Along with the above-mentioned modifications, many researchers have attempted to develop a different morphology of GCN-based metal-free catalytic systems, including GCN in the form of nanotubes [154], nanofibers [155], tubular [156], and nanorods [157] for the effective photodegradation of organic dyes. For instance, GCN nanotubes were more highly photoactive for the degradation of MB compared to bulk GCN or P25 [158]. In addition, its catalytic performance and photocurrent efficiencies were also 1.5-2.0 times higher compared to g- $\mathrm{C}_{3} \mathrm{~N}_{4}$ nanoplates. In another study, a nanofiber-like GCN catalyst exhibited superior catalytic activity for the degradation of $\mathrm{RhB}$ upon the illumination of visible light [159]. Tahir et al. utilized a visible light-responsive tubular GCN catalyst for the degradation of $\mathrm{MB}$ and $\mathrm{MO}$, showing more activity compared to BCN. This was ascribed to the large surface area, along with high visible light absorption in addition to high separation of charge/transfer [156,157]. We compiled the reports on some non-metals such as S, P, C, O, and B co-doped GCN-based catalysts employed for environmental depollution applications (Table 2). 
Table 2. Summary of the metal-free GCN-based catalysts for photocatalytic degradation of organic dyes.

\begin{tabular}{|c|c|c|c|c|c|}
\hline Photocatalyst & Precursor & Dye & Experimental Condition & Comments & Ref. \\
\hline $\mathrm{PTCNs}^{a}$ & $\begin{array}{c}\mathrm{MA}+ \\
\text { Liq. } \mathrm{NH}_{3}\end{array}$ & $\operatorname{RhB}$ & $\begin{array}{l}5 \mathrm{mg} \text { of catalyst, } 20 \mathrm{~mL} \text { of dye solution }\left(70 \mathrm{mg} \mathrm{L}^{-1}\right) \text { and } \\
\text { visible light }(450 \mathrm{~W}, \mathrm{Hg} \text { lamp) by a cutoff filter } \\
(\lambda>380 \mathrm{~nm})\end{array}$ & $\begin{array}{l}S_{\mathrm{BET}}: 107.4 \mathrm{~m}^{2} \mathrm{~g}^{-1}, B_{\mathrm{G}}: 2.63 \mathrm{eV}, k_{\mathrm{RhB}}: \\
\left.0.04491 \mathrm{~min}^{-1}\right) ; \text { Four times recycled. }\end{array}$ & Zhao et al. [134] \\
\hline $\mathrm{B}-\mathrm{N}_{\mathrm{V}}{ }^{b}-\mathrm{GCN}$ & $\mathrm{BA}+\mathrm{MA}$ & MB & $\begin{array}{l}100 \mathrm{~g} \text { of catalyst, } 100 \mathrm{~mL} \text { of dye solution }\left(20 \mathrm{mg} \mathrm{L}^{-1}\right) \text { and } \\
\text { visible light (metal halide lamp, } 300 \mathrm{~W}) .\end{array}$ & $\begin{array}{l}S_{\mathrm{BET}}: 27.0 \mathrm{~m}^{2} \mathrm{~g}^{-1}, B_{\mathrm{G}}: 2.63 \mathrm{eV} ; k_{\mathrm{MB}}: \\
0.03 \mathrm{~min}^{-1} \text {, Three times recycled. }\end{array}$ & Mao et al. [140] \\
\hline$h-\mathrm{BN}^{c} / \mathrm{GCN}$ & DCA & $\mathrm{RhB}$ & $\begin{array}{l}50 \mathrm{mg} \text { of catalyst, } 100 \mathrm{~mL} \text { of dye solution }\left(20 \mathrm{mg} \mathrm{L}^{-1}\right) \text { and } \\
\text { visible light ( } 300 \mathrm{~W} \text { Xe lamp) with a } 420 \mathrm{~nm} \text { cut-off filter. }\end{array}$ & $\begin{array}{l}S_{\mathrm{BET}}: 34.69 \mathrm{~m}^{2} \mathrm{~g}^{-1}, B_{\mathrm{G}}: 2.56 \mathrm{eV}, k_{\mathrm{RhB}}: \\
0.13097 \mathrm{~min}^{-1} \text {, Five times recycled. }\end{array}$ & Jiang et al. [141] \\
\hline $\mathrm{B}^{d}$-doped GCN & $\mathrm{MA}+\mathrm{BO}^{o}$ & $\mathrm{RhB}$ and $\mathrm{MO}$ & $\begin{array}{l}200 \mathrm{mg} \text { of catalyst, } 100 \mathrm{~mL} \text { of dye solution }\left(4 \mathrm{mg} \mathrm{L}^{-1}\right) \\
\text { visible light ( } 300 \mathrm{~W} \text { Xe lamp) with cutoff filter } \mathrm{L}^{-1} \text { and a } \\
\text { water filter. }\end{array}$ & $\begin{array}{l}S_{\mathrm{BET}}: 30 \mathrm{~m}^{2} \mathrm{~g}^{-1}, B_{\mathrm{G}}: 2.66 \mathrm{eV} \text {, Three } \\
\text { times recycled. }\end{array}$ & Yan et al. [142] \\
\hline $\begin{array}{l}\mathrm{S}, \mathrm{P}^{e} \text {-doped GCN } \\
\text { nanorods }\end{array}$ & $\begin{array}{c}\mathrm{TU}^{p}+ \\
\left(\mathrm{NH}_{4}\right)_{2} \mathrm{HPO}_{4}\end{array}$ & $\mathrm{RhB}$ & $\begin{array}{l}50 \mathrm{mg} \text { of catalyst, } 200 \mathrm{~mL} \text { of dye solution }(10 \mathrm{ppm}) \text { and } \\
\text { visible light }(250 \mathrm{~W}) \text {, high-pressure Na lamp with a } 0.5 \mathrm{M} \\
\mathrm{NaNO}_{2} \text { solution filter. }\end{array}$ & $\begin{array}{l}S_{\mathrm{BET}}: 13.6 \mathrm{~m}^{2} \mathrm{~g}^{-1}, B_{\mathrm{G}}: 2.53 \mathrm{eV}, k_{\mathrm{RhB}}: \\
0.026 \mathrm{~min}^{-1}, \text { Three times recycled. }\end{array}$ & Hu et al. [143] \\
\hline $\begin{array}{l}\alpha-S @ G C N \\
\text { core-shell }\end{array}$ & $\begin{array}{c}\mathrm{MA}+ \\
\mathrm{Na}_{2} \mathrm{~S}_{2} \mathrm{O}_{3} \cdot 2 \mathrm{H}_{2} \mathrm{O}\end{array}$ & $\mathrm{RhB}$ & $\begin{array}{l}80 \mathrm{mg} \text { of catalyst, } 80 \mathrm{~mL} \text { of dye solution }\left(5 \mathrm{mg} \mathrm{L}^{-1}\right) \text { and } \\
\text { visible light }(300 \mathrm{~W}, \mathrm{Xe} \mathrm{lamp}) \\
\text { Light intensity }=30 \mathrm{~mW} \mathrm{~cm}^{-2} .\end{array}$ & $\begin{array}{l}S_{\mathrm{BET}}: 13.6 \mathrm{~m}^{2} \mathrm{~g}^{-1}, B_{\mathrm{G}}: 3.03 \mathrm{eV}, k_{\mathrm{RhB}}: \\
0.0382 \mathrm{~min}^{-1} \text {, Three times recycled. }\end{array}$ & Dang et al. [144] \\
\hline $\mathrm{SL}^{f}$-GCN & MA & $\mathrm{RhB}$ & $\begin{array}{l}10 \mathrm{mg} \text { of catalyst, } 50 \mathrm{~mL} \text { of dye solution }\left(10 \mathrm{mg} \mathrm{L}^{-1}\right) \text { and } \\
\text { visible light (Xe lamp, } 100 \mathrm{~mW} \mathrm{~cm}{ }^{2}, \lambda>400 \mathrm{~nm} .\end{array}$ & $\begin{array}{l}S_{\mathrm{BET}}: 13.6 \mathrm{~m}^{2} \mathrm{~g}^{-1}, B_{\mathrm{G}}: 2.9 \mathrm{eV}, k: \\
1.96 \mathrm{~h}^{-1} \text {, Ten times recycled. }\end{array}$ & Zhao et al. [146] \\
\hline $\mathrm{BBA}^{g}-\mathrm{GCN}$ & $\mathrm{DCA}+\mathrm{BBA}$ & $\mathrm{RhB}$ & $\begin{array}{l}100 \mathrm{~g} \text { of catalyst, } 100 \mathrm{~mL} \text { of dye solution }\left(5 \mathrm{mg} \mathrm{L}^{-1}\right) \text { and } \\
\text { visible light ( } 125 \mathrm{~W} \text {, Xe lamp) with a } 420 \mathrm{~nm} \text { cut-off filter. }\end{array}$ & $\begin{array}{l}S_{\mathrm{BET}}: 175.38 \mathrm{~m}^{2} \mathrm{~g}^{-1}, k_{\mathrm{RhB}}: \\
\left.0.02031 \mathrm{~min}^{-1}\right) ; \text { Four times recycled. }\end{array}$ & Zou et al. [147] \\
\hline GCN & MA & $\mathrm{MO}$ & $\begin{array}{l}300 \mathrm{mg} \text { of catalyst, } 100 \mathrm{~mL} \text { of dye solution }\left(0.4 \mathrm{mg} \mathrm{L}^{-1}\right) \text {, } \\
\text { and visible light lamp ( } 300 \mathrm{~W} \text {, Xe lamp) with cutoff filter } \\
\text { L42 and a water filter. }\end{array}$ & $\begin{array}{l}S_{\mathrm{BET}}: 8 \mathrm{~m}^{2} \mathrm{~g}^{-1}, B_{\mathrm{G}}: 2.75 \mathrm{eV} \\
\text { Three times recycled. }\end{array}$ & Yan et al. [148] \\
\hline PCNS $g^{h}$ & MA & MB & $\begin{array}{l}10 \mathrm{mg} \text { of catalyst, } 1.2 \times 10^{-5} \mathrm{M} \text { of dye solution, and } \\
\text { visible light }(500 \mathrm{~W}, \mathrm{Xe} \text { lamp) equipped with UV cut-off } \\
\text { filter }(>420 \mathrm{~nm})\end{array}$ & $\begin{array}{l}S_{\mathrm{BET}}: 190.1 \mathrm{~m}^{2} \mathrm{~g}^{-1}, B_{\mathrm{G}}: 2.82 \mathrm{eV}, k_{\mathrm{MB}}: \\
0.551 \mathrm{~h}^{-1}, \text { Five times recycled. }\end{array}$ & Xu et al. [149] \\
\hline S-pg-GCN ${ }^{i}$ & $\begin{array}{c}\mathrm{MA}+ \\
\text { TTCA }^{q}\end{array}$ & $\mathrm{RhB}$ & $\begin{array}{l}100 \mathrm{mg} \text { of catalyst, } 100 \mathrm{~mL} \text { of dye solution }\left(10 \mathrm{mg} \mathrm{L}^{-1}\right) \text {, } \\
\text { visible light ( } 500 \mathrm{~W} \text { Xe lamp) with a } 400 \mathrm{~nm} \text { cutoff filter }\end{array}$ & $\begin{array}{l}S_{\mathrm{BET}}: 20-52 \mathrm{~m}^{2} \mathrm{~g}^{-1}, B_{\mathrm{G}}: 2.56 \mathrm{eV}, k_{\mathrm{RhB}}: \\
0.0176 \mathrm{~min}^{-1}, \text { Four times recycled. }\end{array}$ & Fan et al. [150] \\
\hline $\mathrm{C}^{j}$-doped GCN & $\mathrm{U}+\mathrm{TU}$ & $\mathrm{TC}^{s}$ & $\begin{array}{l}40 \mathrm{mg} \text { of catalyst, } 80 \mathrm{~mL} \text { of } 10^{-4} \mathrm{M} \mathrm{TC} \text {, Sunlight } \\
(07 / 10 / 2015 \text {, Trivandrum, India, between } 11 \mathrm{p} . \mathrm{m} . \text { and } \\
1 \text { p.m., } 78,000-80,000 \text { lux). }\end{array}$ & $\begin{array}{l}S_{\mathrm{BET}}: 151 \mathrm{~m}^{2} \mathrm{~g}^{-1}, B_{\mathrm{G}}: 2.54 \mathrm{eV} \\
\text { Five times recycled. }\end{array}$ & Panneri et al. [151] \\
\hline
\end{tabular}


Table 2. Cont.

\begin{tabular}{|c|c|c|c|c|c|}
\hline Photocatalyst & Precursor & Dye & Experimental Condition & Comments & Ref. \\
\hline $\begin{array}{l}\text { S,O }{ }^{k} \text { co-doped } \\
\text { GCN }\end{array}$ & DCA & $\mathrm{RhB}$ & $\begin{array}{l}50 \mathrm{mg} \text { of catalyst, } 50 \mathrm{~mL} \text { of dye solution }(10 \mathrm{ppm}) \text {, visible } \\
\text { light }(500 \mathrm{~W} \text {, Xe lamp) with a } 420 \mathrm{~nm} \text { cut-off filter. }\end{array}$ & $B_{\mathrm{G}}: 2.3 \mathrm{eV}$, Four times recycled. & You et al. [152] \\
\hline $\mathrm{TE}^{l}-\mathrm{GCN}$ & MA & $\mathrm{RhB}$ & $\begin{array}{l}50 \mathrm{mg} \text { of catalyst, } 50 \mathrm{~mL} \text { dye solution, visible light ( } 500 \mathrm{~W} \\
\text { UV lamp). }\end{array}$ & $\begin{array}{l}S_{\mathrm{BET}}: 54.3 \mathrm{~m}^{2} \mathrm{~g}^{-1}, B_{\mathrm{G}}: 2.79 \mathrm{eV}, k_{\mathrm{RhB}}: \\
0.0358 \mathrm{~min}^{-1} \text {, Eleven times recycled. }\end{array}$ & Yuan et al. [153] \\
\hline GCN Nanotubes & MA & MB & $\begin{array}{l}50 \mathrm{mg} \text { of catalyst, } 100 \mathrm{~mL} \text { of dye solution }\left(10 \mathrm{mg} \mathrm{L}^{-1}\right) \\
\text { visible light ( } 300 \mathrm{~W}, \text { Xe lamp) with a } 420 \mathrm{~nm} \text { cut-off filter. }\end{array}$ & $\begin{array}{l}S_{\mathrm{BET}}: 10 \mathrm{~m}^{2} \mathrm{~g}^{-1}, B_{\mathrm{G}}: 2.64 \mathrm{eV}, k_{\mathrm{RhB}}: \\
\left(0.01 \mathrm{~min}^{-1}\right) \text {, Not recycled. }\end{array}$ & Wang et al. [154] \\
\hline GCN Nanofibers & MA & $\mathrm{RhB}$ & $\begin{array}{l}100 \text { mg of catalyst, } 0.4 \mathrm{~L} \text { of dye solution }(0.01 \mathrm{M}) \text {, visible } \\
\text { light ( } 500 \mathrm{~W} \text {, Xe lamp). }\end{array}$ & $\begin{array}{l}S_{\mathrm{BET}}: 165 \mathrm{~m}^{2} \mathrm{~g}^{-1}, B_{\mathrm{G}}: 2.80 \mathrm{eV}, k_{\mathrm{RhB}}: \\
0.0412 \mathrm{~min}^{-1}, \text { Three times recycled }\end{array}$ & Tahir et al. [155] \\
\hline GCN Tubulars & MA & $\mathrm{MO}$ and $\mathrm{MB}$ & $\begin{array}{l}100 \mathrm{mg} \text { of catalyst, } 40 \mathrm{~mL} \text { of dye solution }\left(10 \mathrm{mg} \mathrm{L}^{-1}\right) \\
\text { visible light ( } 500 \mathrm{~W} \text { Xe lamp) with a } 420 \mathrm{~nm} \text { cut-off filter. }\end{array}$ & $\begin{array}{l}S_{\mathrm{BET}}: 182.61 \mathrm{~m}^{2} \mathrm{~g}^{-1}, B_{\mathrm{G}}: 2.85 \mathrm{eV}, k_{\mathrm{MB}}: \\
0.02116 \mathrm{~min}^{-1}, k_{\mathrm{MO}}: 0.0067 \mathrm{~min}^{-1} \\
\text { Three times recycled. }\end{array}$ & Tahir et al. [156] \\
\hline GCN Nanorods & DCA & MB & $\begin{array}{l}25 \mathrm{mg} \text { of catalyst, } 50 \mathrm{~mL} \text { of dye solution }(0.03 \mathrm{mM}) \\
\text { visible light ( } 500 \mathrm{~W} \text { Xe lamp) with a } 420 \mathrm{~nm} \text { cut-off filter. }\end{array}$ & $\begin{array}{l}S_{\mathrm{BET}}: 182.61 \mathrm{~m}^{2} \mathrm{~g}^{-1}, B_{\mathrm{G}}: 2.66 \mathrm{eV}, k_{\mathrm{MB}}: \\
0.14812 \mathrm{~h}^{-1} \text {, Three times recycled. }\end{array}$ & Bai et al. [157] \\
\hline $\mathrm{PTI}^{m}$ & MA & MB & $\begin{array}{l}50 \mathrm{mg} \text { of catalyst, } 100 \mathrm{~mL} \text { of dye solution }\left(10 \mathrm{mg} \mathrm{L}^{-1}\right) \\
\text { pH 7, visible light ( } 300 \mathrm{~W} \text { Xe lamp) with a water filter. }\end{array}$ & $\begin{array}{l}S_{\mathrm{BET}}: 96 \mathrm{~m}^{2} \mathrm{~g}^{-1}, B_{\mathrm{G}}: 3.28 \mathrm{eV}, k_{\mathrm{MB}}: \\
1.5 \times 10^{-3} \mathrm{~min}^{-1}, \\
\text { Three times recycled. }\end{array}$ & Heymann et al. [159] \\
\hline $\mathrm{CN} x$ & $\begin{array}{l}\mathrm{LiNO}_{3} \text { and } \\
\mathrm{C}_{3} \mathrm{~N}_{3} \mathrm{Cl}_{3}\end{array}$ & MB & $\begin{array}{l}\text { Catalyst }\left(1.0 \mathrm{mg} \mathrm{L}^{-1}\right) \text {, dye solution }\left(10 \mathrm{mg} \mathrm{L}^{-1}\right) \text {, visible } \\
\text { light ( } 500 \mathrm{~W} \mathrm{Hg-Xe} \mathrm{lamp)} \mathrm{with} \mathrm{a} \mathrm{filter.}\end{array}$ & $\begin{array}{l}S_{\mathrm{BET}}: 24.5 \mathrm{~m}^{2} \mathrm{~g}^{-1}, B_{\mathrm{G}}: 2.4 \mathrm{eV}, k_{\mathrm{MB}}: \\
0.0098 \mathrm{~min}^{-1}, \text { Four times recycled. }\end{array}$ & Tan et al. [160] \\
\hline $\mathrm{HM}-\mathrm{CN}^{n}$ & $\mathrm{U}+\mathrm{TU}$ & MB & $\begin{array}{l}10 \mathrm{mg} \text { of catalyst, } 50 \mathrm{~mL} \text { of dye solution }\left(10 \mathrm{mg} \cdot \mathrm{L}^{-1}\right) \text { and } \\
\text { visible light }(150 \mathrm{~W} \text { Xe lamp) }\end{array}$ & $\begin{array}{l}S_{\mathrm{BET}}: 119.53 \mathrm{~m}^{2} \mathrm{~g}^{-1}, B_{\mathrm{G}}: 2.11 \mathrm{eV}, k_{\mathrm{MB}}: \\
0.125 \mathrm{~min}^{-1} \text {, Not recycled. }\end{array}$ & Zhou et al. [161] \\
\hline $\begin{array}{l}\text { Ultrathin GCN } \\
\text { NSs }\end{array}$ & $\mathrm{U}^{r}$ & $\mathrm{RhB}$ & $\begin{array}{l}100 \mathrm{mg} \text { of catalyst, } 100 \mathrm{~mL} \text { of dye solution }\left(20 \mathrm{mg} \mathrm{L}^{-1}\right) \text {, } \\
\text { visible light ( } 300 \mathrm{~W} \text { Xe lamp), cut-off filter }>420 \mathrm{~nm} .\end{array}$ & $\begin{array}{l}S_{\mathrm{BET}}: 131.2 \mathrm{~m}^{2} \mathrm{~g}^{-1}, B_{\mathrm{G}}: 2.80 \mathrm{eV}, k_{\mathrm{RhB}}: \\
0.07346 \mathrm{~min}^{-1}, \text { Four times recycled. }\end{array}$ & Yang et al. [162] \\
\hline GCN & DCA & BDE209 & $\begin{array}{l}20 \mathrm{mg} \text { of catalyst, } 20 \mathrm{~mL} \text { of } 1 \times 10^{-3} \mathrm{~mol} \mathrm{~L}^{-1} \text { BDE209 } \\
\text { solution, visible light ( } 300 \mathrm{~W} \text {, Xe lamp), } \\
\text { cut-off filter }>360 \mathrm{~nm} \text {. }\end{array}$ & $\begin{array}{l}B_{\mathrm{G}}: 2.7 \mathrm{eV}, k_{\mathrm{BDE} 209}: 0.057 \pm 0.01 \mathrm{~min}^{-1} \\
\text { Not recycled. }\end{array}$ & Sun et al. [163] \\
\hline
\end{tabular}




\section{Porous Carbon Nanocomposites for Catalysis}

Porous carbon nanocomposites act as active phases in catalytic reactions, and they represent a sustainable and green direction for catalysis research $[164,165]$. Nano-structured porous carbons are a wide variety of carbon allotropes including porous graphite, amorphous carbons (porous carbon black, and activated carbon fiber), and carbon nanotubes (CNTs). New developments in the improvement of the properties and performance of a variety of functionalized porous carbons reported during the last five years are also described [166]. Several potential applications of these materials including catalysis, sensing, drug delivery, carbon capture, adsorption, and separation as well as energy storage as displayed in Figure 5.

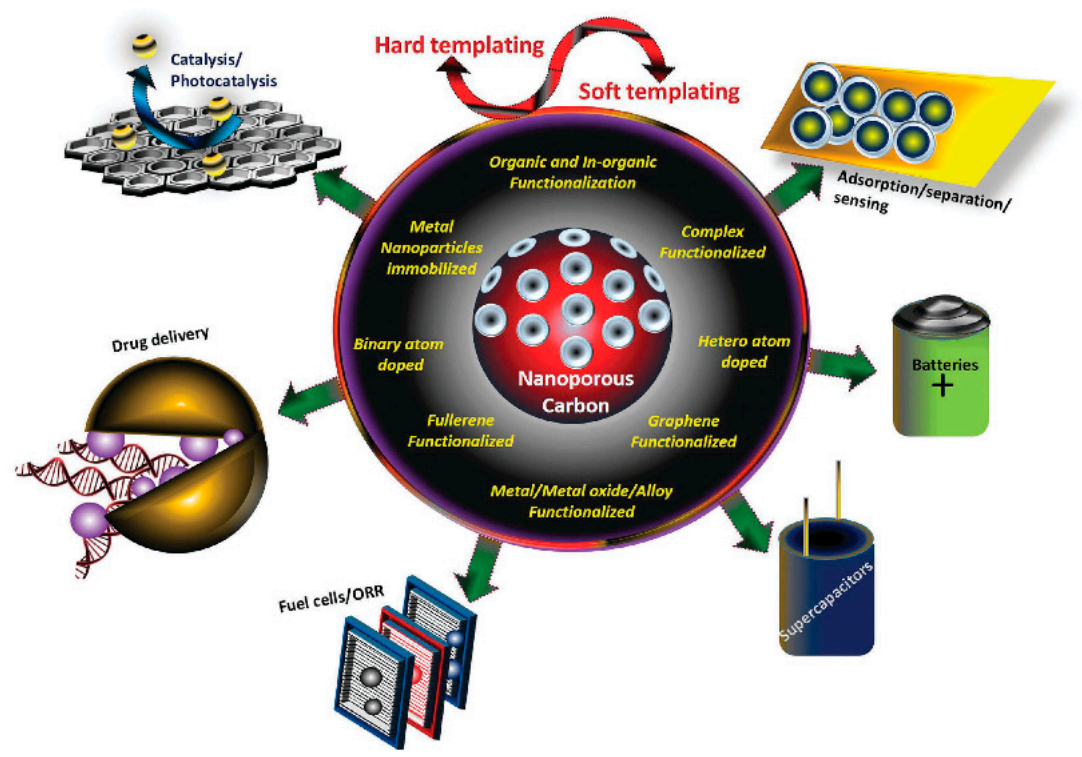

Figure 5. Schematic illustration of the preparation, functionalization and novel applications of micro/mesoporous carbons. From Benzigar et al. [166]. Reprinted with permission from [166]. The Royal Society of Chemistry, 2018.

The most commonly used materials are activated carbons because they have high surface area, and are commercially available at low-cost. After introducing appropriate carboxyl, amine and other functionalities onto nanocomposite surface, it exhibited a better catalytic activity with high selectivity compared with bare carbons [167]. Carbon nanomaterials hold a huge potential in various applications such as medicine, advanced materials, and electronics, due to their unique physical and chemical properties. In addition, carbon nanomaterials can be efficiently used as catalyst supports or as metal-free catalysts in several relevant catalytic processes $[168,169]$. The past decade has witnessed an ever-increasing amount of publications on these topics (Figure 6). The inset shows the number of publications on carbon nanotubes and graphene for comparison [170].

Hydrogenation of aromatic compounds is an increasingly prominent class of hydrotreating reaction in coal, petroleum industries and organic transformations in organic chemistry [171]. For instance, Sun et al. [172,173] reported an efficient method for arenes and polycyclic arenes hydrogenation at $300{ }^{\circ} \mathrm{C}$ using ACs. Interestingly, based on the catalytic hydrogenation and the molecular structures, the relationship between the reactivities of aromatic rings and the mechanism for hydrogen transfer was discussed. In this study, special attention has been given to the selective hydrogenation of PAs, because of important aromatic and hydroaromatic products obtaining from coal, and petroleum materials. 


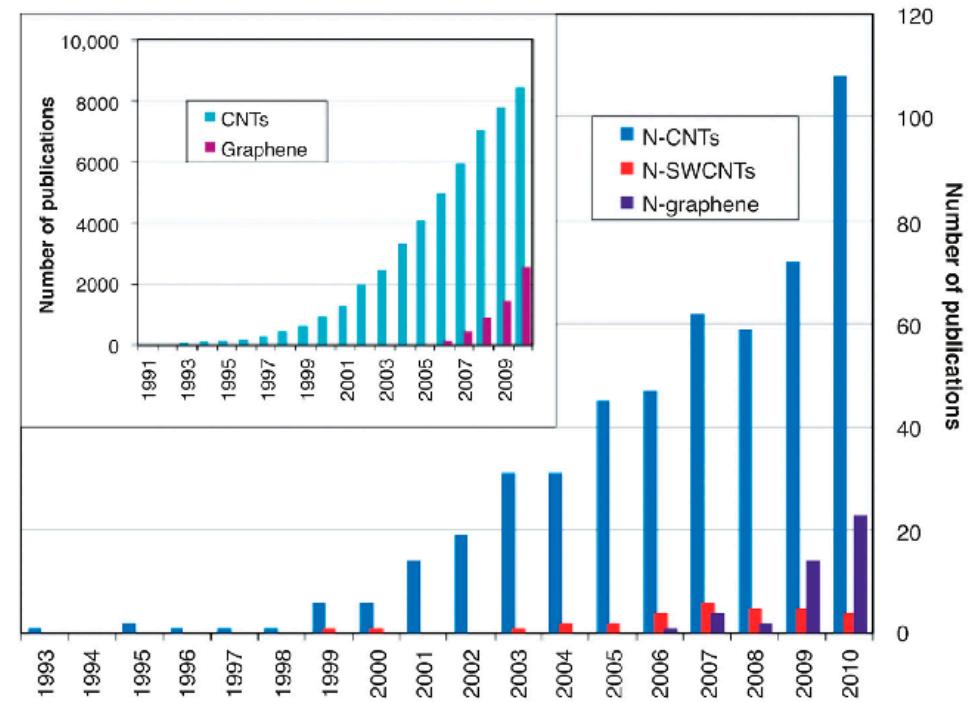

Figure 6. Evolution of the number of publications on $\mathrm{N}$-doped carbon nanotubes, N-doped single-walled carbon nanotubes, and N-doped graphene published annually from 1993 to 2010. From Duong-Viet et al. [169]. Reprinted with permission from [169]. Elsevier, 2016.

On the other hand, the activated carbon originating from different precursors or materials contains an uncontrolled distribution of pore sizes and preserves several impurities such as sulphur, metals, etc. [174] Their application in industries is limited, owing to their large microporosity, insufficient mechanical properties, and low density [175]. For obtaining narrow pore size distribution (PSD) with a low proportion of micropores, mesoporous carbon as a catalyst was developed [176]. Murray et al. [177] reported that the selective hydrogenation of olefins to alkanes was obtained using carbon blacks and hydrazine under aerobic conditions (Scheme 19). This reaction continued with a variety of sensitive functional groups tolerance via a diimide intermediate. Note that carbon surface was chemisorbed by a reductant $\mathrm{N}_{2} \mathrm{H}_{4}$ for attenuating its oxidative reactivity in order to permit its selective hydrogenation. This protocol containing a low-cost solid may enable the catalysis of a variety of substrate transformations.

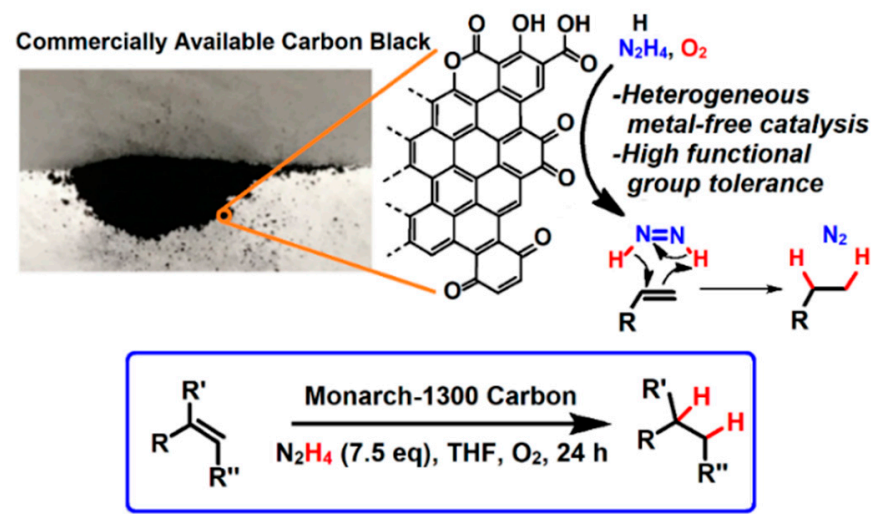

Scheme 19. Monarch 1300 carbon-catalyzed hydrogenation reaction. From Murry et al. [177]. Reprinted with permission from [177]. The American Chemical Society, 2017.

Gupta et al. [178] reported an effective method for the preparation of phosgene gas by nitrogen-modified carbon nanomaterials, which was derived from the $\mathrm{N}$-modified polymer material. The incorporation of active nitrogen into graphitic carbon materials resulted in the formation of porous carbon catalysts that are active and stable for the generation of phosgene $\left(\mathrm{COCl}_{2}\right)$ with very high selectivity. In another study, Lin et al. [179] demonstrated a high temperature-annealed ultradispersed nanodiamond (ADD) catalyst that is used for simple, green, and selective oxidation of benzylic 
alcohols with $t$ - $\mathrm{BuOOH}$ under mild conditions to produce their corresponding derivatives with a conversion rate from 7 to $18.6 \%$. The reaction mechanism of ADD-mediated catalytic processes is shown in Scheme 20.

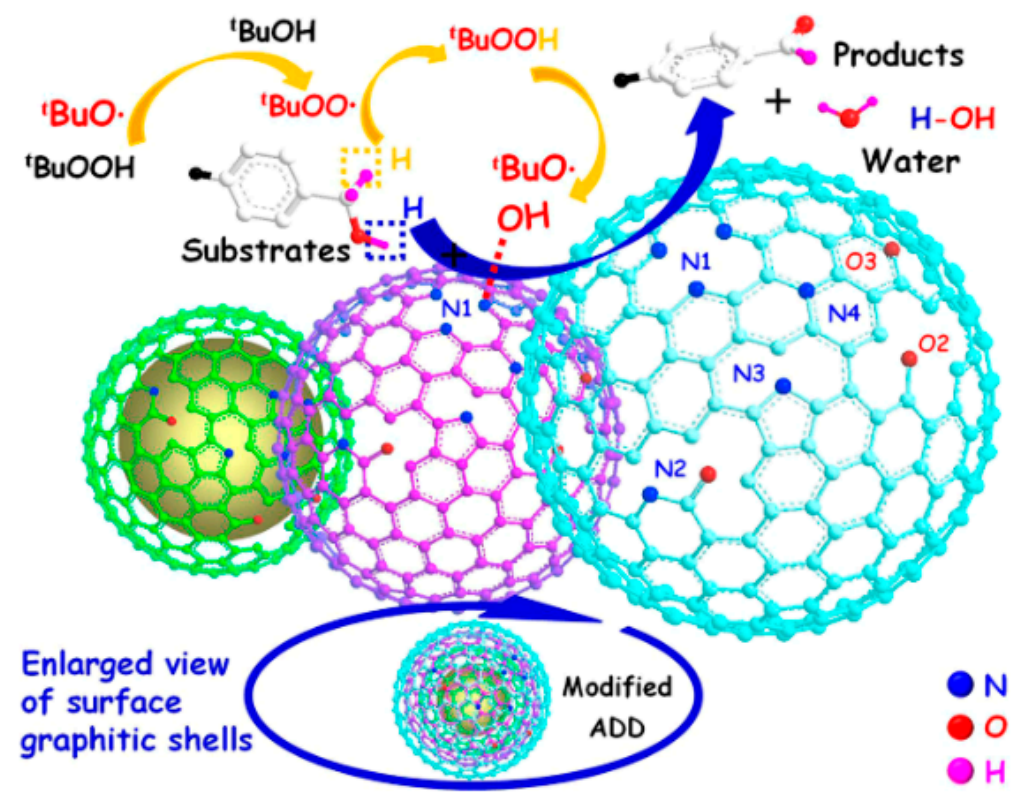

Scheme 20. Catalytic oxidation of benzylic alcohols over an Annealed ultradispersed nanodiamond (ADD) catalyst. From Lin et al. [179]. Reprinted with permission from [179]. The American Chemical Society, 2014.

Wang et al. [180] demonstrated the preparation of a N-containing ordered mesoporous carbon (NOMC) catalyst, which was obtained by introducing $\mathrm{N}$ into the ordered mesoporous carbon during the co-assembly step between m-aminophenol (MAP) and pluronic ${ }^{\circledR} \mathrm{F}-127$ in aqueous medium. It was found that NOMC catalyst underwent the oxidation of ethylbenzene, to produce a conversion rate of $63.3 \%$, along with the selectivity of $84.1 \%$. The synthesis route of NOMC and its catalytic behavior is depicted (Scheme 21).

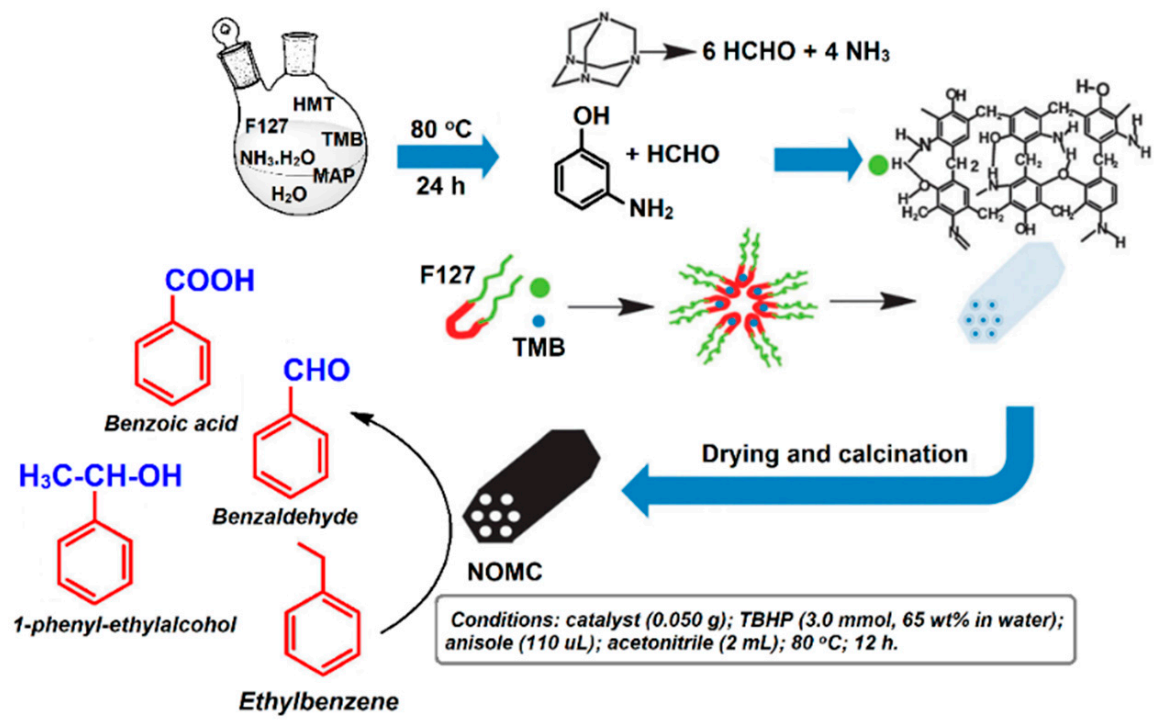

Scheme 21. Schematic representation of the preparation route of $\mathrm{N}$-containing ordered mesoporous carbon (NOMC) and the catalytic oxidation of ethylbenzene. From Wang et al. [180]. Reprinted with permission from [180]. The Royal Society of Chemistry, 2014. 
Watanabe and co-workers [181] developed an effective protocol for conjugated alcohol oxidation using graphitic $\mathrm{N}$-doped activated carbon (AC) in $\mathrm{EtOH}$ under an air atmosphere (Scheme 22). For the oxidation of benzyl and cinnamyl alcohols, a 100\% selectivity was achieved within 5 and $15 \mathrm{~h}$, respectively, using this catalyst. This catalyst was also active with 5-(hydroxymethyl)-2-furaldehyde to afford a $24 \%$ conversion with a selectivity of $93 \%$. However, non-conjugated alcohols did not undergo an oxidation process upon reacting with this catalyst. For the oxidation of a conjugated alcohols, the conjugated system may activate carbon bonding to the $\mathrm{OH}$ group for easy oxidation. In comparison with traditional $\mathrm{Pt} / \mathrm{C}$ and $\mathrm{Ru} / \mathrm{C}$ catalysts, the performance of this catalyst was good under similar reaction conditions. Recyclability studies showed that this catalyst lost its activity after the first run.

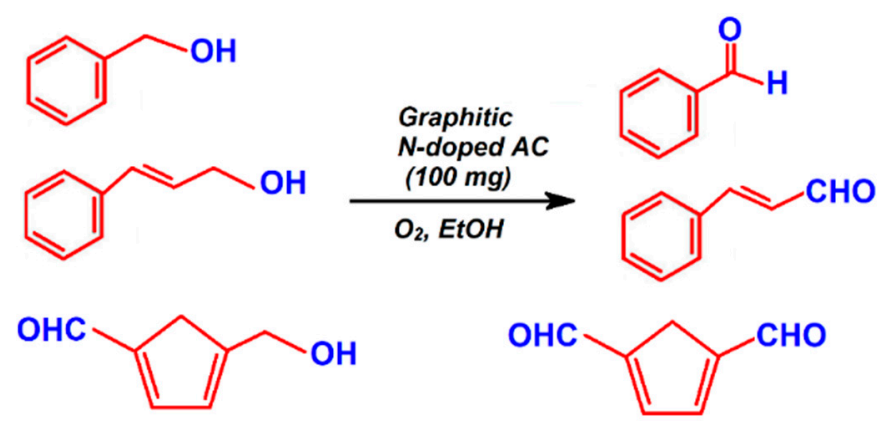

Scheme 22. Oxidation of alcohols in the presence of graphitic N-doped AC catalyst.

In addition, they exhibited catalytic activity towards the reduction of nitrobenzene [182], 4-nitrophenol [183], transesterification [184], oxidative coupling [185], and dehydrochlorination reactions [186]. Moreover, two excellent reviews highlight the active sites and advantages of functionalized micro- and mesoporous carbon materials for metal-free carbon-based catalysts [187,188].

\section{Prospect}

For the development of greener and sustainable routes in organic transformations, impressive sign of progress have been made in the past decades by employing carbocatalysts in a wide range of reactions, including olefin oxidation, sulfoxidation, hydrogenation, Michael addition, $\mathrm{C}-\mathrm{C}$, $\mathrm{C}-\mathrm{N}$ coupling, and so forth. This review highlights the important developments of carbon-based nanocatalysts for these most distinguished organic transformations. Notably, a metal-free catalyst is comparatively cheap and efficient for many industrially and biologically important reactions. Various chemical and physical synthetic strategies have been adopted for the preparation of these carbocatalysts with well-controlled size, shape, and surface modification. Thanks to the effective efforts of scientists and researchers in related fields, much progress has been achieved in the direction of the synthesis and characterization of these carbocatalysts and their applications to various organic transformations. However, the discovery of porous materials have been the main choice for metal-free catalysts in catalytic applications, because of their special physiochemical properties, including large surface area and pore volumes, active sites, low toxicity, and chemically modifiable surfaces. The application of carbocatalysts chemistry helps to reduce the reaction time but allows for a high yield. A variety of surface functional groups can be generated upon the bonding or doping of heteroatoms such as N, O, P, S, B, etc., to defects in metal-free carbon catalysts. Thus, the development of hetero-atom doped carbon catalysts that are favorable characteristics such as facile separation, durability, and recycling capability, as well as fulfilling the concept of sustainable chemistry should be the main objectives for future Research and Development (R\&D) research.

Despite intensive research carried out in this area, there exist numerous challenges in the application of these materials. The gas phase reaction of oxidative dehydrogenation of alkanes using carbon materials is still limited and therefore its application is required. Even though several carbocatalysts showed superior catalytic activities, there are still several challenges that hinder 
carbon material commercialization, including insufficient durability/reliability, corrosion, and catalytic activity in many organic transformations. For example, the exact location of heteroatoms, the nature of their active sites in carbon materials, and their doping mechanism are still not clear. For industrial applications, it is more important to optimize reaction parameters for the large-scale production of carbocatalysts with high product purity and yield, at low costs. The exploration of diversified synthetic routes to fine-tune the properties of carbon-based nanomaterials continues to play a vital role in improving the existing technologies and discovering new applications including energy storage, fuel cells, water-treatment adsorbents, etc. With all these challenges still present in the battlefield, and with growing interest in heterogeneous metal-free catalysis, the use of carbocatalysts will explore other applications in synthetic hetero-coupling bond formation reactions for the fine chemical industry.

Author Contributions: P.V., T.S. and K.-C.L. conceived and designed the experiments; P.V. and P.T. wrote the entire article.

Funding: This research was funded by Ministry of Science and Technology (MOST), Taiwan, grant number [NSC 102-2113-M-002-009-MY3].

Acknowledgments: The authors thank the Ministry of Science and Technology (MOST) and Academia Sinica, Taiwan, for financial supports.

Conflicts of Interest: The authors declare no conflict of interest.

\section{Abbreviations and Acronyms}

AC

Activated carbon

AP-GO Amine functionalized graphene oxide

ATC Ammonium thiocyanate

BCN Bulk graphitic carbon nitride

CPMs Carbon porous materials

$\mathrm{CFs} \quad$ Carbon fibers

CB Carbon black

CNTs Carbon nanotubes

CNDs Carbon nanodots

CA Cyanamide

DCA Dicyandiamide

Gr Graphene

GO Graphene oxide

GCN Graphitic carbon nitride

h-BN Hexagonal-boron nitride

HMT Hexamethylenetetramine

HOMO Highest occupied molecular orbital

LUMO Lowest unoccupied molecular orbital

MA Melamine

MB Methylene blue

MO Methyl orange

ND Nanodiamond

NPC N-doped porous carbon

N-RGO N-doped reduced graphene oxide

OMCs Ordered mesoporous carbon

PCNS Porous graphitic carbon nitride nanosheets

RhB Rhodamine B

TC Tetracycline

TU Thiourea

UV Ultra-violet

U Urea 


\section{References}

1. Zhang, P.; Zhu, H.; Dai, S. Porous carbon supports: Recent advances with various morphologies and compositions. Chem CatChem 2015, 7, 2788-2805. [CrossRef]

2. Wang, H.; Gao, Q.; Hu, J. High hydrogen storage capacity of porous carbons prepared by using activated carbon. J. Am. Chem. Soc. 2009, 131, 7016-7022. [CrossRef] [PubMed]

3. Sevilla, M.; Mokaya, R. Energy storage applications of activated carbons: Supercapacitors and hydrogen storage. Energy Environ. Sci. 2014, 7, 1250-1280. [CrossRef]

4. Veerakumar, P.; Madhu, R.; Chen, S.-M.; Hung, C.-T.; Tang, P.-H.; Wang, C.-B.; Liu, S.-B. Porous carbon-modified electrodes as highly selective and sensitive sensors for detection of dopamine. Analyst 2014, 139, 4994-5000. [CrossRef] [PubMed]

5. Tang, P.; Hu, G.; Li, M.; Ma, D. Graphene-based metal-free catalysts for catalytic reactions in the liquid phase. ACS Catal. 2016, 6, 6948-6958. [CrossRef]

6. Serp, P.; Machado, B. Nanostructured Carbon Materials for Catalysis; The Royal Society of Chemistry: Cambridge, UK, 2015; ISSN 1757-6725.

7. Lam, E.; Luong, J.H.T. Carbon materials as catalyst supports and catalysts in the transformation of biomass to fuels and chemicals. ACS Catal. 2014, 4, 3393-3410. [CrossRef]

8. Xiaoyan, S.; Rui, W.; Dangsheng, S. Research progress in metal-free carbon-based catalysts. Chin. J. Catal. 2013, 34, 508-523.

9. Nakajima, K.; Hara, M. Amorphous carbon with $\mathrm{SO}_{3} \mathrm{H}$ groups as a solid brønsted acid catalyst. ACS Catal. 2012, 2, 1296-1304. [CrossRef]

10. Dutta, S.; Bohre, A.; Zheng, W.; Jenness, G.R.; Núñez, M.; Saha, B.; Vlachos, D.G. Solventless C-C coupling of low carbon furanics to high carbon fuel precursors using an improved graphene oxide carbocatalyst. ACS Catal. 2017, 7, 3905-3915. [CrossRef]

11. Haag, D.; Kung, H.H. Metal free graphene based catalysts: A review. Top. Catal. 2014, 57, 762-773. [CrossRef]

12. Shearer, C.J.; Cherevan, A.; Eder, D. Application and future challenges of functional nanocarbon hybrids. Adv. Mater. 2014, 26, 2295-2318. [CrossRef] [PubMed]

13. Kong, X.K.; Chen, C.L.; Chen, Q.W. Doped graphene for metal-free catalysis. Chem. Soc. Rev. 2014, 43, 2841-2857. [CrossRef] [PubMed]

14. Zhang, J.; Liu, X.; Blume, R.; Zhang, A.; Schlögl, R.; Su, D.S. Surface-modified carbon nanotubes catalyze oxidative dehydrogenation of n-butane. Science 2008, 322, 73-77. [CrossRef] [PubMed]

15. Frank, B.; Morassutto, M.; Schomaecker, R.; Schloegl, R.; Su, D.S. Oxidative dehydrogenation of ethane over multiwalled carbon nanotubes. ChemCatChem 2010, 2, 644-648. [CrossRef]

16. McGregor, J.; Huang, Z.; Parrott, E.P.J.; Zeitler, J.A.; Nguyen, K.L.; Rawson, J.M.; Carley, A.; Hansen, T.W.; Tessonnier, J.-P.; Su, D.S.; et al. Active coke: Carbonaceous materials as catalysts for alkane dehydrogenation. J. Catal. 2010, 269, 329-339. [CrossRef]

17. Rinaldi, A.; Zhang, J.; Frank, B.; Su, D.S.; Hamid, S.B.A.; Schlçgl, R. Oxidative purification of carbon nanotubes and its impact on catalytic performance in oxidative dehydrogenation reactions. ChemSusChem 2010, 3, 254-260. [CrossRef] [PubMed]

18. Dreyer, D.R.; Jia, H.P.; Bielawski, C.W. Graphene oxide: A convenient carbocatalyst for facilitating oxidation and hydration reactions. Angew. Chem. Int. Ed. 2010, 49, 6813-6816. [CrossRef]

19. Zhang, P.; Gong, Y.; Li, H.; Chen, Z.; Wang, Y. Solvent-free aerobic oxidation of hydrocarbons and alcohols with Pd@N-doped carbon from glucose. Nat. Commun. 2013, 4, 1593. [CrossRef] [PubMed]

20. Chen, Y.; Zhang, J.; Zhang, M.; Wang, X. Molecular and textural engineering of conjugated carbon nitride catalysts for selective oxidation of alcohols with visible light. Chem. Sci. 2013, 4, 3244-3248. [CrossRef]

21. Huang, H.; Huang, J.; Liu, Y.-M.; He, H.-Y.; Cao, Y.; Fan, K.-N. Graphite oxide as an efficient and durable metal-free catalyst for aerobic oxidative coupling of amines to imines. Green Chem. 2012, 14, 930-934. [CrossRef]

22. Dreyer, D.R.; Jia, H.-P.; Todd, A.D.; Geng, J.; Bielawski, C.W. Graphite oxide: A selective and highly efficient oxidant of thiols and sulfides. Org. Biomol. Chem. 2011, 9, 7292-7295. [CrossRef] [PubMed]

23. Chen, H.; He, M.; Wang, Y.; Zhai, L.; Cui, Y.; Li, Y.; Li, Y.; Zhou, H.; Hong, X.; Denga, Z. Metal-free direct amidation of peptidyl thiol esters with $\alpha$-amino acid esters. Green Chem. 2011, 13, 2723-2726. [CrossRef] 
24. Jia, H.-P.; Dreyer, D.R.; Bielawski, C.W. C-H oxidation using graphite oxide. Tetrahedron 2011, 67, 4431-4464. [CrossRef]

25. Ahmad, H.; Fana, M.; Hui, D. Graphene oxide incorporated functional materials: A review. Composites $B$ 2018, 145, 270-280. [CrossRef]

26. Boukhvalov, D.V.; Dreyer, D.R.; Bielawski, C.W.; Soon, Y.-W. A computational investigation of the catalytic properties of graphene oxide: Exploring mechanisms by using DFT methods. ChemCatChem 2012, 4, 1844-1849. [CrossRef]

27. Dhakshinamoorthy, A.; He, J.; Franconetti, A.; Asiri, A.M.; Primo, A.; Garcia, H. Defective graphene as a metal-free catalyst for chemoselective olefin hydrogenation by hydrazine. Catal. Sci. Technol. 2018, 8, 1589-1598. [CrossRef]

28. Vijay, K.A.; Rao, K.R. Recyclable graphite oxide catalyzed Friedel-Crafts addition of indoles to $\alpha, \beta$-unsaturated ketones. Tetrahedron Lett. 2011, 52, 5188-5191. [CrossRef]

29. Favaretto, L.; An, J.; Sambo, M.; Nisi, A.D.; Bettini, C.; Melucci, M.; Kovtun, A.; Liscio, A.; Palermo, V.; Bottoni, A.; et al. Graphene oxide promotes site-selective allylic alkylation of thiophenes with alcohols. Org. Lett. 2018, 20, 3705-3709. [CrossRef] [PubMed]

30. Acocella, M.R.; Mauro, M.; Falivene, L.; Cavallo, L.; Guerra, G. Inverting the diastereoselectivity of the Mukaiyama-Michael addition with graphite-based catalysts. ACS Catal. 2014, 4, 492-496. [CrossRef]

31. Acocella, M.R.; Pascale, M.D.; Maggio, M.; Guerra, G. Graphite oxide as catalyst for diastereoselective Mukaiyama aldol reaction of 2-(trimethylsilyloxy) furan in solvent free conditions. J. Mol. Catal. A 2015, 408, 237-241. [CrossRef]

32. Dreyer, D.R.; Jarvis, K.A.; Ferriera, P.J.; Bielawski, C.W. Graphite oxide as a dehydrative polymerization catalyst: A one-step synthesis of carbon-reinforced poly (phenylene methylene) composites. Macromolecules 2011, 44, 7659-7667. [CrossRef]

33. Mauro, M.; Acocella, M.R.; Corcione, C.E.; Maffezzoli, A.; Guerra, G. Catalytic activity of graphite-based nanofillers on cure reaction of epoxy resins. Polymer 2014, 55, 5612-5615. [CrossRef]

34. Dhakshinamoorthy, A.; Alvaro, M.; Concepcion, P.; Fornes, V.; Garcia, H. Graphene oxide as an acid catalyst for the room temperature ring opening of epoxides. Chem. Commun. 2012, 48, 5443-5445. [CrossRef] [PubMed]

35. Acocella, M.R.; Mauro, M.; Guerra, G. Regio- and Enantioselective Friedel-Crafts reactions of indoles to epoxides catalyzed by graphene oxide: A green approach. ChemSusChem 2014, 7, 3279-3283. [CrossRef] [PubMed]

36. Roy, B.; Ghosh, S.; Ghosh, P.; Basu, B. Graphene oxide (GO) or reduced graphene oxide (rGO): Efficient catalysts for one-pot metal-free synthesis of quinoxalines from 2-nitroaniline. Tetrahedron Lett. 2015, 56, 6762-6767. [CrossRef]

37. Kundu, S.; Basu, B. Graphene oxide (GO)-catalyzed multi-component reactions: Green synthesis of library of pharmacophore 3-sulfenylimidazo[1,2-a]pyridines. RSC Adv. 2015, 5, 50178-50185. [CrossRef]

38. Furimsky, E. Carbon materials for catalysis. J. Am. Chem. Soc. 2009, 131, 9856-9857. [CrossRef]

39. Sengupta, A.; Su, C.L.; Bao, C.L.; Nai, C.T.; Loh, K.P. Graphene oxide and its functionalized derivatives as carbocatalysts in the multicomponent strecker reaction of ketones. ChemCatChem 2014, 6, 2507-2511. [CrossRef]

40. Su, D.S.; Perathoner, S.; Centi, G. Nanocarbons for the development of advanced catalysts. Chem. Rev. 2013, 113, 5782-5816. [CrossRef] [PubMed]

41. Duan, X.; Sun, H.; Wang, S. Metal-free carbocatalysis in advanced oxidation reactions. Acc. Chem. Res. 2018, 51, 678-687. [CrossRef] [PubMed]

42. Su, C.; Loh, K.P. Carbocatalysts: Graphene oxide and its derivatives. Acc. Chem. Res. 2013, 46, $2275-2285$. [CrossRef] [PubMed]

43. Machado, B.F.; Serp, P. Graphene-based materials for catalysis. Catal. Sci. Technol. 2012, 2, 54-75. [CrossRef]

44. Jamatia, R.; Gupta, A.; Dam, B.; Saha, M.; Pal, A.K. Graphite oxide: A metal free highly efficient carbocatalyst for the synthesis of 1,5-benzodiazepines under room temperature and solvent free heating conditions. Green Chem. 2017, 19, 1576-1585. [CrossRef]

45. Mohammadi, O.; Golestanzadeh, M.; Abdouss, M. Recent advances in organic reactions catalyzed by graphene oxide and sulfonated graphene as heterogeneous nanocatalysts: A review. New J. Chem. 2017, 41, 11471-11497. [CrossRef] 
46. Wang, A.; Wang, C.; Fu, L.; Wong-Ng, W.; Lan, Y. Recent advances of graphitic carbon nitride-based structures and applications in catalyst, sensing, imaging, and LEDs. Nano-Micro Lett. 2017, 9, 47. [CrossRef]

47. Zhu, J.; Xiao, P.; Li, H.; Carabineiro, S.A.C. Graphitic carbon nitride: Synthesis, properties, and applications in catalysis. ACS Appl. Mater. Interfaces 2014, 6, 16449-16465. [CrossRef] [PubMed]

48. Cao, S.; Low, J.; Yu, J.; Jaroniec, M. Polymeric photocatalysts based on graphitic carbon nitride. Adv. Mater. 2015, 27, 2150-2176. [CrossRef] [PubMed]

49. Nikokavoura, A.; Trapalis, C. Graphene and $\mathrm{g}-\mathrm{C}_{3} \mathrm{~N}_{4}$ based photocatalysts for $\mathrm{NO}_{x}$ removal: A review. Appl. Surf. Sci. 2018, 430, 18-52. [CrossRef]

50. Kumar, S.; Kumar, A.; Bahuguna, A.; Sharma, V.; Krishnan, V. Two-dimensional carbon-based nanocomposites for photocatalytic energy generation and environmental remediation applications. Beilstein J. Nanotechnol. 2017, 8, 1571-1600. [CrossRef] [PubMed]

51. Sudhaik, A.; Raizada, P.; Shandilya, P.; Jeong, D.-Y.; Lim, J.-H.; Singh, P. Review on fabrication of graphitic carbon nitride based efficient nanocomposites for photodegradation of aqueous phase organic pollutants. J. Ind. Eng. Chem. 2018. [CrossRef]

52. Matos, I.; Bernardo, M.; Fonseca, I. Porous carbon: A versatile material for catalysis. Catal. Today 2017, 285, 194-203. [CrossRef]

53. Serp, P.; Figueiredo, J.L. Carbon Materials for Catalysis; John Wiley \& Sons: New Jersey, NJ, USA, 2009; ISBN 978-0-470-17885-0.

54. Su, D.S.; Wen, G.; Wu, S.; Peng, F.; Schlögl, R. Carbocatalysis in liquid-phase reactions. Angew. Chem. Int. Ed. 2017, 56, 936-964. [CrossRef] [PubMed]

55. Malaika, A.; Wower, K.; Kozłowski, M. Chemically modified activated carbons as catalysts of oxidative dehydrogenation of $n$-butane. Acta Phys. Pol. A 2010, 118, 459-464. [CrossRef]

56. Liu, R.; Li, F.; Chen, C.; Song, Q.; Zhao, N.; Xiao, F. Nitrogen-functionalized reduced graphene oxide as carbocatalysts with enhanced activity for polyaromatic hydrocarbon hydrogenation. Catal. Sci. Technol. 2017, 7, 1217-1226. [CrossRef]

57. Moreno-Castilla, C.; Carrasco-Marín, F.; Parejo-Pérez, C.; López, R.M. Dehydration of methanol to dimethyl ether catalyzed by oxidized activated carbons with varying surface acidic character. Carbon 2001, 39, 869-875. [CrossRef]

58. Szymański, G.S.; Grzybek, T.; Papp, H. Influence of nitrogen surface functionalities on the catalytic activity of activated carbon in low temperature SCR of $\mathrm{NO} x$ with $\mathrm{NH}_{3}$. Catal. Today 2004, 90, 51-59. [CrossRef]

59. Raymundo-Piñero, E.; Cazorla-Amorós, D.; Linares-Solano, A. The role of different nitrogen functional groups on the removal of $\mathrm{SO}_{2}$ from flue gases by $\mathrm{N}$-doped activated carbon powders and fibers. Carbon 2003, 41, 1925-1932. [CrossRef]

60. Li, K.; Ling, L.; Lu, C.; Qiao, W.; Liu, Z.; Liu, L.; Mochida, I. Catalytic removal of $\mathrm{SO}_{2}$ over ammonia-activated carbon fibers. Carbon 2001, 39, 1803-1808. [CrossRef]

61. Faria, P.C.C.; Órfão, J.J.M.; Pereir, M.F.R. A ozone decomposition in water catalyzed by activated carbon: Influence of chemical and textural properties. Ind. Eng. Chem. Res. 2006, 45, 2715-2721. [CrossRef]

62. Gomes, H.T.; Machado, B.F.; Ribeiro, A.; Moreira, I.; Rosário, M.; Silva, A.M.T.; Figueiredo, J.L.; Faria, J.L. Catalytic properties of carbon materials for wet oxidation of aniline. J. Hazard. Mater. 2008, 159, 420-426. [CrossRef] [PubMed]

63. Santos, A.; Yustos, P.; Rodriguez, S.; Garcia-Ochoa, F. Wet oxidation of phenol, cresols and nitrophenols catalyzed by activated carbon in acid and basic media. Appl. Catal. B Environ. 2006, 65, 269-281. [CrossRef]

64. Zhou, H.; Lou, H.; Lu, W. Improving the catalytic efficiency of carbon-based active sites by trace oxide promoters for highly productive olefin synthesis. Catal. Sci. Technol. 2017, 7, 802-806. [CrossRef]

65. Espinosa, J.C.; Navalon, S.; Alvaro, M.; Dhakshinamoorthy, A.; Garcia, H. Reduction of C=C double bonds by hydrazine using active carbons as metal-free catalysts. ACS Sustain. Chem. Eng. 2018, 6, 5607-5614. [CrossRef]

66. Li, M.; Xu, F.; Li, H.; Wang, Y. Nitrogen-doped porous carbon materials: Promising catalysts or catalyst supports for heterogeneous hydrogenation and oxidation. Catal. Sci. Technol. 2016, 6, 3670-3693. [CrossRef]

67. Wang, H.; Maiyalagan, T.; Wang, X. Review on recent progress in nitrogen-doped graphene: Synthesis, characterization, and its potential applications. ACS Catal. 2012, 2, 781-794. [CrossRef]

68. Hu, M.; Yao, Z.; Wang, X. Graphene-based nanomaterials for catalysis. Ind. Eng. Chem. Res. 2017, 56, 3477-3502. [CrossRef] 
69. Navalon, S.; Dhakshinamoorthy, A.; Alvaro, M.; Garcia, H. Carbocatalysis by graphene-based materials. Chem. Rev. 2014, 114, 6179-6212. [CrossRef] [PubMed]

70. Yang, H.; Cui, X.; Dai, X.; Deng, Y.; Shi, F. Carbon-catalysed reductive hydrogen atom transfer reactions. Nat. Commun. 2015, 6, 6478. [CrossRef] [PubMed]

71. Navalón, S.; Herance, J.R.; Álvaro, M.; García, H. General aspects in the use of graphenes in catalysis. Mater. Horiz. 2018, 5, 363-378. [CrossRef]

72. Dhakshinamoorthy, A.; Primo, A.; Concepcion, P.; Alvaro, M.; Garcia, H. Doped graphene as a metal-free carbocatalyst for the selective aerobic oxidation of benzylic hydrocarbons, cyclooctane and styrene. Chem. Eur. J. 2013, 19, 7547-7554. [CrossRef] [PubMed]

73. Dai, B.; Chen, K.; Wang, Y.; Kang, L.; Zhu, M. Boron and nitrogen doping in graphene for the catalysis of acetylene hydrochlorination. ACS Catal. 2015, 5, 2541-2547. [CrossRef]

74. Zhang, S.; Hong, B.; Fan, Z.; Lu, J.; Xu, Y.; Pera-Titus, M. Aquivion-carbon composites with tunable amphiphilicity for pickering interfacial catalysis. ACS Appl. Mater. Interfaces 2018, 10, 26795-26804. [CrossRef] [PubMed]

75. Zhang, F.; Jiang, H.; Wu, X.; Mao, Z.; Li, H. Organoamine-functionalized graphene oxide as a bifunctional carbocatalyst with remarkable acceleration in a one-pot multistep reaction. ACS Appl. Mater. Interfaces 2015, 7, 1669-1677. [CrossRef] [PubMed]

76. Kumari, S.; Shekhar, A.; Mungse, H.P.; Khatri, O.P.; Pathak, D.D. Metal-free one-pot synthesis of amides using graphene oxide as an efficient catalyst. RSC Adv. 2014, 4, 41690-41695. [CrossRef]

77. Zhang, F.; Jiang, H.; Li, X.; Wu, X.; Li, H. Amine-functionalized GO as an active and reusable acid-base bifunctional catalyst for one-pot cascade reactions. ACS Catal. 2014, 4, 394-401. [CrossRef]

78. Majumdar, B.; Sarma, D.; Bhattacharya, T.; Sarma, T.K. Graphene oxide as metal-free catalyst in oxidative dehydrogenative $\mathrm{C}-\mathrm{N}$ coupling leading to $\alpha$-ketoamides: Importance of dual catalytic activity. ACS Sustain. Chem. Eng. 2017, 5, 9286-9294. [CrossRef]

79. Fang, J.; Peng, Z.; Yang, Y.; Wang, J.; Guo, J.; Gong, H. Graphene-oxide-promoted direct dehydrogenative coupling reaction of aromatics. Asian J. Org. Chem. 2018, 7, 355-358. [CrossRef]

80. Dai, Y.; Zhou, J.; Huang, C.; Gu, Q.; Zeng, Y.; Xu, W.; Meng, X.; Fu, W.; Sun, Y. Selective etching of N-doped graphene meshes as metal free catalyst with tunable kinetics, high activity and the origin of new catalytic behaviors. Part. Part. Syst. Charact. 2018, 35, 1700395. [CrossRef]

81. Dai, Y.; Chai, Y.; Sun, Y.; Fu, W.; Wang, X.; Gu, Q.; Zeng, T.H.; Sun, Y. New versatile Pt supports composed of graphene sheets decorated by $\mathrm{Fe}_{2} \mathrm{O}_{3}$ nanorods and N-dopants with high activity based on improved metal/support interactions. J. Mater. Chem. A 2015, 3, 125-130. [CrossRef]

82. Liu, J.; Yan, X.; Wang, L.; Kong, L.; Jian, P. Three-dimensional nitrogen-doped graphene foam as metal-free catalyst for the hydrogenation reduction of p-nitrophenol. J. Colloid Interface Sci. 2017, 497, 102-107. [CrossRef] [PubMed]

83. Song, J.; Kang, S.W.; Lee, Y.W.; Park, Y.; Kim, J.H.; Han, S.W. Regulating the catalytic function of reduced graphene oxides using capping agents for metal-free catalysis. ACS Appl. Mater. Interfaces 2017, 9, 1692-1701. [CrossRef] [PubMed]

84. Kong, X.; Sun, Z.; Chen, M.; Chen, C.; Chen, Q.W. Metal-free catalytic reduction of 4-nitrophenol to 4-aminophenol by N-doped graphene. Energy Environ. Sci. 2013, 6, 3260-3266. [CrossRef]

85. Primo, A.; Neatu, F.; Florea, M.; Parvulescu, V.; Garcia, H. Graphenes in the absence of metals as carbocatalysts for selective acetylene hydrogenation and alkene hydrogenation. Nat. Commun. 2014, 5, 5291. [CrossRef] [PubMed]

86. Zhang, J.; Li, S.; Deng, G.-J.; Gong, H. Metal-free, oxidant-free, and controllable graphene oxide catalyzed direct iodination of arenes and ketones. ChemCatChem 2018, 10, 376-380. [CrossRef]

87. Kim, Y.; Some, S.; Lee, H. Graphene oxide as a recyclable phase transfer catalyst. Chem. Commun. 2013, 49, 5702-5704. [CrossRef] [PubMed]

88. Gao, Y.; Tang, P.; Zhou, H.; Zhang, W.; Yang, H.; Yan, N.; Hu, G.; Mei, D.; Wang, J.; Ma, D. Graphene oxide catalyzed $\mathrm{C}-\mathrm{H}$ bond activation: The importance of oxygen functional groups for biaryl construction. Angew. Chem. Int. Ed. 2016, 55, 3124-3128. [CrossRef] [PubMed]

89. Dhakshinamoorthy, A.; Alvaro, M.; Puche, M.; Fornes, V.; Garcia, H. Graphene oxide as catalyst for the acetalization of aldehydes at room temperature. ChemCatChem 2012, 4, 2026-2030. [CrossRef] 
90. Basu, B.; Kundu, S.; Sengupta, D. Graphene oxide as a carbocatalyst: The first example of a one-pot sequential dehydration-hydrothiolation of secondary aryl alcohols. RSC Adv. 2013, 3, 22130-22134. [CrossRef]

91. Nagai, M.; Isoe, R.; Ishiguro, K.; Tominaga, H.; Shimizu, M. Graphite and graphene oxides catalyze bromination or alkylation in reaction of phenol with $t$-butylbromide. Chem. Eng. J. 2012, 207, 938-942. [CrossRef]

92. Goncalves, G.A.B.; Pires, S.M.G.; Simoes, M.M.Q.; Neves, M.G.P.M.S.; Marques, P.A.A.P. Three-dimensional graphene oxide: A promising green and sustainable catalyst for oxidation reactions at room temperature. Chem. Commun. 2014, 50, 7673-7676. [CrossRef] [PubMed]

93. Sedrpoushan, A.; Heidari, M.; Akhavan, O. Nanoscale graphene oxide sheets as highly efficient carbocatalysts in green oxidation of benzylic alcohols and aromatic aldehydes. Chin. J. Catal. 2017, 38, 745-757. [CrossRef]

94. Mungse, H.P.; Bhakuni, N.; Tripathi, D.; Sharma, O.P.; Sain, B.; Khatri, O.P. Fractional distribution of graphene oxide and its potential as an efficient and reusable solid catalyst for esterification reactions. J. Phys. Org. Chem. 2014, 27, 944-951. [CrossRef]

95. Ghiaci, M.; Ghazaie, M. Modification of a heterogeneous catalyst: Sulfonated graphene oxide coated by $\mathrm{SiO}_{2}$ as an efficient catalyst for Beckmann rearrangement. Catal. Commun. 2016, 87, 70-73. [CrossRef]

96. Mirza-Aghayan, M.; Tavana, M.M.; Boukherroub, R. Sulfonated reduced graphene oxide as a highly efficient catalyst for direct amidation of carboxylic acids with amines using ultrasonic irradiation. Ultrason. Sonochem. 2016, 29, 371-379. [CrossRef] [PubMed]

97. Ji, J.; Zhang, G.; Chen, H.; Wang, S.; Zhang, G.; Zhang, F.; Fan, X. Sulfonated graphene as water-tolerant solid acid catalyst. Chem. Sci. 2011, 2, 484-487. [CrossRef]

98. Bermudez, J.M.; Menendez, J.A.; Arenillas, A.; MartinezPalou, R.; Romero, A.A.; Luque, R. Selectivity matters: Graphene oxide-mediated oxidative coupling of benzylamine to N-benzylidine-1-phenylmethanamine under microwave irradiation. J. Mol. Catal. A Chem. 2015, 406, 19-22. [CrossRef]

99. Acocella, M.R.; D’Urso, L.; Maggio, M.; Guerra, G. Green region- and enantioselective aminolysis catalyzed by graphite and graphene oxide under solvent-free conditions. ChemCatChem 2016, 8, 1915-1920. [CrossRef]

100. Verma, S.; Mungse, H.P.; Kumar, N.; Choudhary, S.; Jain, S.L.; Sain, B.; Khatri, O.P. Graphene oxide: An efficient and reusable carbocatalyst for aza-Michael addition of amines to activated alkenes. Chem. Commun. 2011, 47, 12673-12675. [CrossRef] [PubMed]

101. Long, Z.; Sun, L.; Zhu, W.; Chen, G.; Wang, X.; Sun, W. P-Doped carbons derived from cellulose as highly efficient metal-free catalysts for aerobic oxidation of benzyl alcohol in water under an air atmosphere. Chem. Commun. 2018, 54, 8991-8994. [CrossRef] [PubMed]

102. Su, F.Z.; Mathew, S.C.; Mçhlmann, L.; Antonietti, M.; Wang, X.C.; Blechert, S. Aerobic oxidative coupling of amines by carbon nitride photocatalysis with visible light. Angew. Chem. Int. Ed. 2011, 50, 657-660. [CrossRef] [PubMed]

103. Dong, F.; Zhao, Z.; Xiong, T.; Ni, Z.; Zhang, W.; Sun, Y.; Ho, W.-K. In Situ construction of g-C ${ }_{3} \mathrm{~N}_{4} / g-\mathrm{C}_{3} \mathrm{~N}_{4}$ metal-free heterojunction for enhanced visible-light photocatalysis. ACS Appl. Mater. Interfaces 2013, 5, 11392-11401. [CrossRef] [PubMed]

104. Masih, D.; Ma, Y.; Rohani, S. Graphitic $\mathrm{C}_{3} \mathrm{~N}_{4}$ based noble-metal-free photocatalyst systems: A review. Appl. Catal. B 2017, 206, 556-588. [CrossRef]

105. Hu, C.; Dai, L. Carbon-based metal-free catalysts for electrocatalysis beyond the ORR. Angew. Chem. Int. Ed. 2016, 55, 11736-11758. [CrossRef] [PubMed]

106. Jin, X.; Balasubramanian, V.V.; Selvan, S.T.; Sawant, D.P.; Chari, M.A.; Lu, G.Q.; Vinu, A. Highly ordered mesoporous carbon nitride nanoparticles with high nitrogen content: A metal-free basic catalyst. Angew. Chem. Int. Ed. 2009, 48, 7884-7887. [CrossRef] [PubMed]

107. Wang, X.; Blechert, S.; Antonietti, M. Polymeric graphitic carbon nitride for heterogeneous photocatalysis. ACS Catal. 2012, 2, 1596-1606. [CrossRef]

108. Ong, W.-J.; Tan, L.-L.; Ng, Y.H.; Yong, S.-T.; Chai, S.-P. Graphitic carbon nitride $\left(\mathrm{g}_{-} \mathrm{C}_{3} \mathrm{~N}_{4}\right)$-based photocatalysts for artificial photosynthesis and environmental remediation: Are we a step closer to achieving sustainability? Chem. Rev. 2016, 116, 7159-7329. [CrossRef] [PubMed]

109. Zhang, H.; Zuo, X.; Tang, H.; Li, G.; Zhou, Z. Origin of photoactivity in graphitic carbon nitride and strategies for enhancement of photocatalytic efficiency: Insights from first principles computations. Phys. Chem. Chem. Phys. 2015, 17, 6280-6288. [CrossRef] [PubMed] 
110. Wang, Y.; Wang, X.C.; Antonietti, M. Polymeric graphitic carbon nitride as a heterogeneous organocatalyst: From photochemistry to multipurpose catalysis to sustainable chemistry. Angew. Chem. Int. Ed. 2012, 51, 68-89. [CrossRef] [PubMed]

111. Shi, L.; Wang, T.; Zhang, H.; Chang, K.; Ye, J. Electrostatic self-assembly of nanosized carbon nitride nanosheet onto a zirconium metal-organic framework for enhanced photocatalytic $\mathrm{CO}_{2}$ reduction. Adv. Funct. Mater. 2015, 25, 5360-5367. [CrossRef]

112. Su, F.Z.; Mathew, S.C.; Lipner, G.; Fu, X.Z.; Antonietti, M.; Blechert, S.; Wang, X.C. mpg-C $\mathrm{N}_{4} \mathrm{~N}_{\text {-catalyzed }}$ selective oxidation of alcohols using $\mathrm{O}_{2}$ and visible light. J. Am. Chem. Soc. 2010, 132, 16299-16301. [CrossRef] [PubMed]

113. Chen, X.F.; Zhang, J.S.; Fu, X.Z.; Antonietti, M.; Wang, X.C. Fe-gC $\mathrm{C}_{3} \mathrm{~N}_{4}$-catalyzed oxidation of benzene to phenol using hydrogen peroxide and visible light. J. Am. Chem. Soc. 2009, 131, 11658-11659. [CrossRef] [PubMed]

114. Wang, Y.; Li, H.R.; Yao, J.; Wang, X.C.; Antonietti, M. Synthesis of boron doped polymeric carbon nitride solids and their use as metal-free catalysts for aliphatic C-H bond oxidation. Chem. Sci. 2011, 2, 446-450. [CrossRef]

115. Zheng, Y.; Lin, L.; Wang, B.; Wang, X. Graphitic carbon nitride polymers toward sustainable photoredox catalysis. Angew. Chem. Int. Ed. 2015, 54, 12868-12884.

116. Goettmann, F.; Fischer, A.; Antonietti, M.; Thomas, A. Chemical synthesis of mesoporous carbon nitrides using hard templates and their use as a metal-free catalyst for Friedel-Crafts reaction of benzene. Angew. Chem. Int. Ed. 2006, 45, 4467-4471. [CrossRef] [PubMed]

117. Liu, H.; Li, H.; Lu, J.; Zeng, S.; Wang, M.; Luo, N.; Xu, S.; Wang, F. Photocatalytic cleavage of C-C bond in lignin models under visible light on mesoporous graphitic carbon nitride through $\pi-\pi$ stacking interaction. ACS Catal. 2018, 8, 4761-4771. [CrossRef]

118. Hu, C.; Hung, W.-Z.; Wang, M.-S.; Lu, P.-J. Phosphorus and sulfur codoped $\mathrm{g}-\mathrm{C}_{3} \mathrm{~N}_{4}$ as an efficient metal-free photocatalyst. Carbon 2018, 127, 374-383. [CrossRef]

119. Lakhi, K.S.; Park, D.-H.; Al-Bahily, K.; Cha, W.; Viswanathan, B.; Choy, J.-H.; Vinu, A. Mesoporous carbon nitrides: Synthesis, functionalization, and applications. Chem. Soc. Rev. 2017, 46, 72-101. [CrossRef] [PubMed]

120. Li, J.; Cui, W.; Sun, Y.; Chu, Y.; Cen, W.; Dong, F. Directional electron delivery via a vertical channel between g- $\mathrm{C}_{3} \mathrm{~N}_{4}$ layers promotes photocatalytic efficiency. J. Mater. Chem. A 2017, 5, 9358-9364. [CrossRef]

121. Chen, Q.; Zhao, Y.; Huang, X.; Chen, N.; Qu, L. Three-dimensional graphitic carbon nitride functionalized graphene-based high-performance supercapacitors. J. Mater. Chem. A 2015, 3, 6761-6766.

122. Zhu, Y.-P.; Ren, T.-Z.; Yuan, Z.-Y. Mesoporous phosphorus-doped g- $\mathrm{C}_{3} \mathrm{~N}_{4}$ nanostructured flowers with superior photocatalytic hydrogen evolution performance. ACS Appl. Mater. Interfaces 2015, 7, 16850-16856. [CrossRef] [PubMed]

123. Wen, J.; Xie, J.; Chen, X.; Li, X. A review on g- $\mathrm{C}_{3} \mathrm{~N}_{4}$-based photocatalysts. Appl. Surf. Sci. 2017, 391, 72-123. [CrossRef]

124. Zhang, L.; Wang, H.; Qin, Z.; Wang, J.; Fan, W. Synthesis of two-dimensional mesoporous carbon nitride under different carbonization temperatures and investigation of its catalytic properties in knoevenagel condensations. RSC Adv. 2015, 5, 22838-22846. [CrossRef]

125. Xu, J.; Shang, J.-K.; Jiang, Q.; Wang, Y.; Li, Y.-X. Facile alkali-assisted synthesis of g- $_{3} \mathrm{~N}_{4}$ materials and their high-performance catalytic application in solvent-free cycloaddition of $\mathrm{CO}_{2}$ to epoxides. RSC Adv. 2016, 6, 55382-55392. [CrossRef]

126. Tian, C.; Lu, C.; Wang, B.; Xie, X.; Miao, Y.; Li, X. Mesoporous carbon nitride as a basic catalyst in dehydrochlorination of 1,1,2-trichloroethane into 1,1-dichloroethene. RSC Adv. 2015, 5, 103829-103833. [CrossRef]

127. Xu, J.; Long, K.-Z.; Chen, T.; Xue, B.; Li, Y.-X.; Cao, Y. Mesostructured graphitic carbon nitride as a new base catalyst for the efficient synthesis of dimethyl carbonate by transesterification. Catal. Sci. Technol. 2013, 3, 3192-3199. [CrossRef]

128. Min, B.-H.; Ansari, M.B.; Mo, Y.-H.; Park, S.-E. Mesoporous carbon nitride synthesized by nanocasting with urea/formaldehyde and metal-free catalytic oxidation of cyclic olefins. Catal. Today 2013, 204, 156-163. [CrossRef] 
129. Fang, S.; Lv, K.; Li, Q.; Ye, H.; Du, D.; Li, M. Effect of acid on the photocatalytic degradation of rhodamine B over g- $_{3} \mathrm{~N}_{4}$. Appl. Surf. Sci. 2015, 358, 336-342. [CrossRef]

130. Veerakumar, P.; Chen, S.-M.; Madhu, R.; Veeramani, V.; Hung, C.-T.; Liu, S.-B. Nickel nanoparticle-decorated porous carbons for highly active catalytic reduction of organic dyes and sensitive detection of $\mathrm{Hg}$ (II) ions. ACS Appl. Mater. Interfaces 2015, 7, 24810-24821. [CrossRef] [PubMed]

131. Luo, L.; Zhang, A.; Janik, M.J.; Li, K.; Song, C.; Guo, X. Facile fabrication of ordered mesoporous graphitic carbon nitride for RhB photocatalytic degradation. Appl. Surf. Sci. 2017, 396, 78-84. [CrossRef]

132. Luo, L.; Zhang, A.; Janik, M.J.; Li, K.; Song, C.; Guo, X. Inorganic salt-assisted fabrication of graphitic carbon nitride with enhanced photocatalytic degradation of Rhodamine, B. Mater. Lett. 2017, 188, 130-133. [CrossRef]

133. Chai, B.; Yan, J.; Wang, C.; Ren, Z.; Zhu, Y. Enhanced visible light photocatalytic degradation of Rhodamine B over phosphorus doped graphitic carbon nitride. Appl. Surf. Sci. 2017, 391, 376-383. [CrossRef]

134. Zhao, R.; Gao, J.; Mei, S.; Wu, Y.; Wang, X.; Zhai, X.; Yang, J.; Hao, C.; Yan, J. Facile synthesis of graphitic $\mathrm{C}_{3} \mathrm{~N}_{4}$ nanoporous tube with high enhancement of visible-light photocatalytic activity. Nanotechnology 2017, 28, 495710. [CrossRef] [PubMed]

135. Yang, Q.; Wang, W.; Zhao, Y.; Zhu, J.; Zhu, Y.; Wang, L. Metal-free mesoporous carbon nitride catalyze the Friedel-Crafts reaction by activation of benzene. RSC Adv. 2015, 5, 54978-54984. [CrossRef]

136. Xu, J.; Wang, Y.; Shang, J.-K.; Jiang, Q.; Li, Y.-X. Synthesis of mesoporous carbon nitride via a novel detemplation method and its superior performance in base-catalyzed reactions. Catal. Sci. Technol. 2016, 6, 4192-4200. [CrossRef]

137. Zhao, Z.; Dai, Y.; Lin, J.; Wang, G. Highly-ordered mesoporous carbon nitride with ultrahigh surface area and pore volume as a superior dehydrogenation catalyst. Chem. Mater. 2014, 26, 3151-3161. [CrossRef]

138. Ma, X.; Lv, Y.; Xu, J.; Liu, Y.; Zhang, R.; Zhu, Y. A strategy of enhancing the photoactivity of g- $\mathrm{C}_{3} \mathrm{~N}_{4}$ via doping of nonmetal elements: A first-principles study. J. Phys. Chem. C 2012, 116, 23485-23493. [CrossRef]

139. Zhu, J.; Diao, T.; Wang, W.; Xu, X.; Sun, X.; Carabineiro, S.A.C.; Zhao, Z. Boron doped graphitic carbon nitride with acid-base duality for cycloaddition of carbon dioxide to epoxide under solvent-free condition. Appl. Catal. B: Environ. 2017, 219, 92-100. [CrossRef]

140. Mao, Y.; Wu, M.; Li, G.; Dai, P.; Yu, X.; Bai1, Z.; Chen, P. Photocatalytic degradation of methylene blue over boron-doped $g-\mathrm{C}_{3} \mathrm{~N}_{4}$ together with nitrogen vacancies under visible light irradiation. Reac. Kinet. Mech. Cat. 2018, 1-12. [CrossRef]

141. Jiang, L.; Yuan, X.; Zeng, G.; Wu, Z.; Liang, J.; Chen, X.; Leng, L.; Wang, H.; Wang, H. Metal-free efficient photocatalyst for stable visible-light photocatalytic degradation of refractory pollutant. Appl. Catal. B Environ. 2018, 221, 715-725. [CrossRef]

142. Yan, S.C.; Li, Z.S.; Zou, Z.G. Photodegradation of rhodamine $B$ and methyl orange over boron-doped g- $C_{3} N_{4}$ under visible light irradiation. Langmuir 2010, 26, 3894-3901. [CrossRef] [PubMed]

143. Hu, S.; Ma, L.; Xie, Y.; Li, F.; Fan, Z.; Wang, F.; Wang, Q.; Wang, Y.; Kang, X.; Wu, G. Hydrothermal synthesis of oxygen functionalized S-P codoped $\mathrm{g}-\mathrm{C}_{3} \mathrm{~N}_{4}$ nanorods with outstanding visible light activity under anoxic conditions. Dalton Trans. 2015, 44, 20889-20897. [CrossRef] [PubMed]

144. Dang, X.; Zhang, X.; Zhang, W.; Dong, X.; Wang, G.; Ma, C.; Zhang, X.; Ma, H.; Xue, M. Ultra-thin $\mathrm{C}_{3} \mathrm{~N}_{4}$ nanosheets for rapid charge transfer in the core-shell heterojunction of $\alpha$-sulfur@ $\mathrm{C}_{3} \mathrm{~N}_{4}$ for superior metal-free photocatalysis under visible light. RSC Adv. 2015, 5, 15052-15058. [CrossRef]

145. Liao, G.; Chen, S.; Quan, X.; Yu, H.; Zhao, H. Graphene oxide modified $g-\mathrm{C}_{3} \mathrm{~N}_{4}$ hybrid with enhanced photocatalytic capability under visible light irradiation. J. Mater. Chem. 2012, 22, 2721-2726. [CrossRef]

146. Zhao, H.; Yu, H.; Quan, X.; Chen, S.; Zhao, H.; Wang, H. Atomic single layer graphitic- $\mathrm{C}_{3} \mathrm{~N}_{4}$ : Fabrication and its high photocatalytic performance under visible light irradiation. RSC Adv. 2014, 4, 624-628. [CrossRef]

147. Zou, H.; Yan, X.; Ren, J.; Wu, X.; Dai, Y.; Sha, D.; Pan, J.; Liu, J. Photocatalytic activity enhancement of modified $\mathrm{g}-\mathrm{C}_{3} \mathrm{~N}_{4}$ by ionothermal copolymerization. J. Materiomics 2015, 1, 340-347. [CrossRef]

148. Yan, S.C.; Li, Z.S.; Zou, Z.G. Photodegradation performance of $\mathrm{g}-\mathrm{C}_{3} \mathrm{~N}_{4}$ fabricated by directly heating melamine. Langmuir 2009, 25, 10397-10401. [CrossRef] [PubMed]

149. Xu, J.; Wang, Z.; Zhu, Y. Enhanced visible-light-driven photocatalytic disinfection performance and organic pollutant degradation activity of porous g- $\mathrm{C}_{3} \mathrm{~N}_{4}$ nanosheets. ACS Appl. Mater. Interfaces 2017, 9, 27727-27735. [CrossRef] [PubMed] 
150. Fan, Q.; Liu, J.; Yu, Y.; Zuo, S.; Li, B. A simple fabrication for sulfur doped graphitic carbon nitride porous rods with excellent photocatalytic activity degrading RhB dye. Appl. Surf. Sci. 2017, 391, 360-368. [CrossRef]

151. Panneri, S.; Ganguly, P.; Mohan, M.; Nair, B.N.; Mohamed, A.A.P.; Warrier, K.G.; Hareesh, U.S. Photoregenerable, bifunctional granules of carbon-doped $\mathrm{g}-\mathrm{C}_{3} \mathrm{~N}_{4}$ as adsorptive photocatalyst for the efficient removal of tetracycline antibiotic. ACS Sustain. Chem. Eng. 2017, 5, 1610-1618. [CrossRef]

152. You, R.; Dou, H.; Chen, L.; Zheng, S.; Zhang, Y. Graphitic carbon nitride with S and O codoping for enhanced visible light photocatalytic performance. RSC Adv. 2017, 7, 15842-15850. [CrossRef]

153. Yuan, X.Y.; Zhou, C.; Jin, Y.R.; Jing, Q.Y.; Yang, Y.L.; Shen, X.; Tang, Q.; Mu, Y.H.; Du, A.K. Facile synthesis of $3 \mathrm{D}$ porous thermally exfoliated $\mathrm{g}-\mathrm{C}_{3} \mathrm{~N}_{4}$ nanosheet with enhanced photocatalytic degradation of organic dye. J. Colloid Interfaces Sci. 2016, 468, 211-219. [CrossRef] [PubMed]

154. Wang, S.; Li, C.; Wang, T.; Zhang, P.; Li, A.; Gong, J. Controllable synthesis of nanotube-type graphitic $\mathrm{C}_{3} \mathrm{~N}_{4}$ and their visible-light photocatalytic and fluorescent properties. J. Mater. Chem. A 2014, 2, 2885-2890. [CrossRef]

155. Tahir, M.; Cao, C.; Mahmood, N.; Butt, F.K.; Mahmood, A.; Idrees, F.; Hussain, S.; Tanveer, M.; Ali, Z.; Aslam, I. Multifunctional g- $\mathrm{C}_{3} \mathrm{~N}_{4}$ nanofibers: A template-free fabrication and enhanced optical, electrochemical, and photocatalyst properties. ACS Appl. Mater. Interfaces 2014, 6, 1258-1265. [CrossRef] [PubMed]

156. Tahir, M.; Cao, C.; Butt, F.K.; Idrees, F.; Mahmood, N.; Ali, Z.; Aslam, I.; Tanveer, M.; Rizwan, M.; Mahmood, T. Tubular graphitic- $\mathrm{C}_{3} \mathrm{~N}_{4}$ : A prospective material for energy storage and green photocatalysis. J. Mater. Chem. A 2013, 1, 13949-13955. [CrossRef]

157. Bai, X.; Wang, L.; Zong, R.; Zhu, Y. Photocatalytic activity enhanced via g- $\mathrm{C}_{3} \mathrm{~N}_{4}$ nanoplates to nanorods. J. Phys. Chem. C 2013, 117, 9952-9961. [CrossRef]

158. Justicia, I.; Ordejon, P.; Canto, G.; Mozos, J.L.; Fraxedas, J.; Battiston, G.A.; Gerbasi, R.; Figueras, A. Designed self-doped titanium oxide thin films for efficient visible-light photocatalysis. Adv. Mater. 2002, 14, 1399-1402. [CrossRef]

159. Heymann, L.; Schiller, B.; Noei, H.; Stierle, A.; Klin, C. A new synthesis approach for carbon nitrides: Poly (triazine imide) and its photocatalytic properties. ACS Omega 2018, 3, 3892-3900. [CrossRef] [PubMed]

160. Tan, J.Z.Y.; Nursam, N.M.; Xia, F.; Sani, M.-A.; Li, W.; Wang, X.; Caruso, R.A. High-performance coral reef-like carbon nitrides: Synthesis and application in photocatalysis and heavy metal ion adsorption. ACS Appl. Mater. Interfaces 2017, 9, 4540-4547. [CrossRef] [PubMed]

161. Zhou, M.; Hou, Z.; Chen, X. Graphitic- $\mathrm{C}_{3} \mathrm{~N}_{4}$ nanosheets: Synergistic effects of hydrogenation and $n / n$ junctions for enhanced photocatalytic activities. Dalton Trans. 2017, 46, 10641-10649. [CrossRef] [PubMed]

162. Yang, Y.; Chen, J.; Mao, Z.; An, N.; Wang, D.; Fahlman, B.D. Ultrathin g- $\mathrm{C}_{3} \mathrm{~N}_{4}$ nanosheets with an extended visible-light-responsive range for significant enhancement of photocatalysis. RSC Adv. 2017, 7, 2333-2341. [CrossRef]

163. Sun, C.; Chen, C.; Ma, W.; Zhao, J. Photocatalytic debromination of decabromodiphenyl ether by graphitic carbon nitride. Sci. China Chem. 2012, 55, 2532-2536. [CrossRef]

164. Liu, L.; Zhu, Y.-P.; Su, M.; Yuan, Z.-Y. Metal-free carbonaceous materials as promising heterogeneous catalysts. ChemCatChem 2015, 7, 2765-2787. [CrossRef]

165. Francisco, R.R. The role of carbon materials in heterogeneous catalysis. Carbon 1998, 36, 159-175.

166. Benzigar, M.R.; Talapaneni, S.N.; Joseph, S.; Ramadass, K.; Singh, G.; Scaranto, J.; Ravon, U.; Al-Bahily, K.; Vinu, A. Recent advances in functionalized micro and mesoporous carbon materials: Synthesis and applications. Chem. Soc. Rev. 2018, 47, 2680-2721. [CrossRef] [PubMed]

167. Shin, Y.; Liu, J.; Wang, L.-Q.; Nie, Z.; Samuels, W.D.; Fryxell, G.E.; Exarhos, G.J. Ordered hierarchical porous materials: Towards tunable size- and shape-selective microcavities in nanoporous channels. Angew. Chem. 2000, 112, 2814-2819. [CrossRef]

168. Garcia, H. Allotropic Carbon nanoforms as advanced metal-free catalysts or as supports. Adv. Chem. 2014, 2014, 906781. [CrossRef]

169. Duong-Viet, C.; Ba, H.; Truong-Phuoc, L.; Liu, Y.; Tessonnier, J.-P.; Nhut, J.-M.; Granger, P.; Pham-Huu, C. Nitrogen-doped carbon composites as metal-free catalysts. New Materials for Catalytic Applications; Parvulescu, V.I., Kemnitz, E., Eds.; Elsevier: New York, NY, USA, 2016; pp. 273-311.

170. Fujita, S.-I.; Yoshida, H.; Arai, M. Nitrogen-doped activated carbon as metal-free catalysts having various functions. J. Carbon Res. 2017, 3, 31. [CrossRef] 
171. Matos, I.; Neves, P.D.; Castanheiro, J.E.; Perez-Mayoral, E.; Martin-Aranda, R.; Duran-Valle, C.; Vital, J.; Botelho do Rego, A.M.; Fonseca, I.M. Mesoporous carbon as an efficient catalyst for alcoholysis and aminolysis of epoxides. Appl. Catal. A Gen. 2012, 439, 24-30. [CrossRef]

172. Sun, L.-B.; Zong, Z.-M.; Kou, J.-H.; Zhang, L.-F.; Ni, Z.-H.; Yu, G.-Y.; Chen, H.; Wei, X.-Y. Activated carbon-catalyzed hydrogenation of polycyclic arenes. Energy Fuels 2004, 18, 1500-1504. [CrossRef]

173. Sun, L.-B.; Wei, X.-Y.; Liu, X.-Q.; Zong, Z.-M.; Li, W.; Kou, J.-H. Selective hydrogen transfer to anthracene and its derivatives over an activated carbon. Energy Fuels 2009, 23, 4877-4882. [CrossRef]

174. Borchardt, L.; Zhu, Q.-L.; Casco, M.E.; Berg, R.; Zhuang, X.; Kaskel, S.; Feng, X.; Xu, Q. Toward a molecular design of porous carbon materials. Mat. Today 2017, 20, 592-610. [CrossRef]

175. Jong, K.P.D.; Geus, J.W. Carbon nanofibers: Catalytic synthesis and applications. Catal. Rev. Sci. Eng. 2000, 42, 481-510. [CrossRef]

176. Antolini, E. Nitrogen-doped carbons by sustainable N- and C-containing natural resources as nonprecious catalysts and catalyst supports for low temperature fuel cells. Renew. Sustain. Energy. Rev. 2016, 58, 34-51. [CrossRef]

177. Murray, A.T.; Surendranath, Y. Reversing the native aerobic oxidation reactivity of graphitic carbon: Heterogeneous metal-free alkene hydrogenation. ACS Catal. 2017, 7, 3307-3312. [CrossRef]

178. Gupta, N.K.; Peng, B.; Haller, G.L.; Ember, E.E.; Lercher, J.A. Nitrogen modified carbon nano-materials as stable catalysts for phosgene synthesis. ACS Catal. 2016, 6, 5843-5855. [CrossRef]

179. Lin, Y.; Su, D. Fabrication of nitrogen-modified annealed nanodiamond with improved catalytic activity. ACS Nano 2014, 8, 7823-7833. [CrossRef] [PubMed]

180. Wang, J.; Liu, H.; Gu, X.; Wang, H.; Su, D.S. Synthesis of nitrogen-containing ordered mesoporous carbon as a metal-free catalyst for selective oxidation of ethylbenzene. Chem. Commun. 2014, 50, 9182-9184. [CrossRef] [PubMed]

181. Watanabe, H.; Asano, S.; Fujita, S.-I.; Yoshida, H.; Arai, M. Nitrogen-doped, metal-free activated carbon catalysts for aerobic oxidation of alcohols. ACS Catal. 2015, 5, 2886-2894. [CrossRef]

182. Fu, H.; Zhu, D. Graphene oxide-facilitated reduction of nitrobenzene in sulfide containing aqueous solutions. Environ. Sci. Technol. 2013, 47, 4204-4210. [CrossRef] [PubMed]

183. Wang, Z.; Su, R.; Wang, D.; Shi, J.; Wang, J.-X.; Pu, Y.; Chen, J.-F. Sulfurized graphene as efficient metal-free catalysts for reduction of 4-nitrophenol to 4-aminophenol. Ind. Eng. Chem. Res. 2017, 56, 13610-13617. [CrossRef]

184. Acocella, M.R.; Maggio, M.; Ambrosio, C.; Aprea, N.; Guerra, G. Oxidized carbon black as an activator of transesterification reactions under solvent-free conditions. ACS Omega 2017, 2, 7862-7867. [CrossRef]

185. Shaikh, M.; Sahu, A.; Kumar, A.K.; Sahu, M.; Singha, S.K.; Ranganath, K.V.S. Metal-free carbon as a catalyst for oxidative coupling: Solvent-enhanced poly-coupling with regioselectivity. Green Chem. 2017, 19, 4533-4537. [CrossRef]

186. Xu, J.; Zhao, X.; Wang, A.; Zhang, T. Synthesis of nitrogen-doped ordered mesoporous carbons for catalytic dehydrochlorination of 1,2-dichloroethane. Carbon 2014, 80, 610-616. [CrossRef]

187. Navalon, S.; Dhakshinamoorthy, A.; Alvaro, M.; Antonietti, M.; García, H. Active sites on graphene-based materials as metal-free catalysts. Chem. Soc. Rev. 2017, 46, 4501-4529. [CrossRef] [PubMed]

188. Yu, D.; Nagelli, E.; Du, F.; Dai, L. Metal-free carbon nanomaterials become more active than metal catalysts and last longer. J. Phys. Chem. Lett. 2010, 1, 2165-2173. [CrossRef]

(C) 2018 by the authors. Licensee MDPI, Basel, Switzerland. This article is an open access article distributed under the terms and conditions of the Creative Commons Attribution (CC BY) license (http://creativecommons.org/licenses/by/4.0/). 